\title{
Regulator of $G$ protein signalling 14 attenuates cardiac remodelling through the MEK-ERK1/2 signalling pathway
}

\author{
Ying $\mathrm{Li}^{1,2} \cdot$ Xiao-hong Tang ${ }^{2} \cdot$ Xiao-hui $\mathrm{Li}^{3} \cdot$ Hai-jiang $\mathrm{Dai}^{2} \cdot \mathrm{Ru}^{2} \mathrm{jia} \mathrm{Miao}^{2} \cdot$ \\ Jing-jing Cai ${ }^{2} \cdot$ Zhi-jun Huang ${ }^{1} \cdot$ Alex F. Chen ${ }^{2} \cdot$ Xiao-wei Xing ${ }^{4} \cdot$ \\ Yao Lu ${ }^{1} \cdot$ Hong Yuan ${ }^{1,2}$
}

Received: 27 October 2015/Accepted: 1 June 2016/Published online: 13 June 2016

(c) The Author(s) 2016. This article is published with open access at Springerlink.com

\begin{abstract}
In the past 10 years, several publications have highlighted the role of the regulator of $\mathrm{G}$ protein signalling (RGS) family in multiple diseases, including cardiovascular diseases. As one of the multifunctional family members, RGS14 is involved in various biological processes, such as synaptic plasticity, cell division, and phagocytosis. However, the role of RGS14 in cardiovascular diseases remains unclear. In the present study, we used a genetic approach to examine the role of RGS14 in pathological cardiac remodelling in vivo and in vitro. We observed that RGS14 was down-regulated in human failing hearts, murine hypertrophic hearts, and isolated hypertrophic cardiomyocytes. Moreover, the extent of aortic banding-induced
\end{abstract}

Electronic supplementary material The online version of this article (doi:10.1007/s00395-016-0566-1) contains supplementary material, which is available to authorized users.

\section{Yao Lu}

luyao0719@163.com

$\triangle$ Hong Yuan

yuanhongxy3@163.com

1 Center of Clinical Pharmacology, The Third Xiangya Hospital, Central South University, 138 Tong-Zi-Po Road, Changsha 410013, Hunan, People's Republic of China

2 Department of Cardiology, The Third Xiangya Hospital, Central South University, 138 Tong-Zi-Po Road, Changsha 410013, Hunan, People's Republic of China

3 Department of Pharmacology, School of Pharmaceutical Sciences, Central South University, Changsha 410078, Hunan, People's Republic of China

4 Center for Experimental Medicine Research, The Third Xiangya Hospital, Central South University, Changsha 410013, Hunan, People's Republic of China cardiac hypertrophy and fibrosis was exacerbated in RGS14 knockout mice, whereas RGS14 transgenic mice exhibited a significantly alleviated response to pressure overload. Furthermore, research of the underlying mechanism revealed that the RGS14-dependent rescue of cardiac remodelling was attributed to the abrogation of mitogenactivated protein kinase (MEK)-extracellular signal-regulated protein kinase (ERK) 1/2 signalling. The results showed that constitutive activation of MEK1 nullified the cardiac protection in RGS14 transgenic mice, and inhibition of MEK-ERK1/2 by U0126 reversed RGS14 deletionrelated hypertrophic aggravation. These results demonstrated that RGS14 attenuated the development of cardiac remodelling through MEK-ERK1/2 signalling. RGS14 exhibited great potential as a target for the treatment of pathological cardiac remodelling.

Keywords Cardiac remodelling - Cardiac dysfunction . RGS14 - MEK1/2 - ERK1/2

\section{Introduction}

Heart failure is the end stage of almost all cardiac diseases, resulting in increased morbidity and mortality. Cardiac remodelling, including hypertrophy and fibrosis, is the major independent risk factor for heart failure, which usually develops in response to hypertension, myocardial infarction, valvular heart disease, and endocrine disorders $[6,26,44]$. In recent decades, distinct signal transduction pathways have been identified to be involved in the development of cardiac remodelling [12, 15, 23, 24]. Among the most prominent signal transducers are the mitogen-activated protein kinase (MAPK), calmodulindependent phosphatase, and JAK-STAT signalling 
pathways $[3,11,18]$, which are largely associated with $\mathrm{G}$ protein-coupled receptor (GPCR)-mediated signalling [56].

GPCRs constitute a large family of receptors that sense molecules outside the cell and activate intracellular signal transduction pathways. These receptors have been widely implicated in the cardiovascular system [54]. Perturbations in GPCR signalling could lead to pathological changes and contribute to various cardiovascular diseases, including hypertension, arrhythmia, and myocardial ischemia. Nearly one-third of the current pharmaceuticals on the market targeting GPCRs, such as angiotensin II receptor blockers, $\beta$-adrenergic receptor blockers, and luteinizing hormonereleasing hormone agonists, have had great success in treating human diseases [7, 32, 33]. Therefore, a better understanding of the modulatory mechanism of GPCRs in hypertrophic hearts might have great significance for improving the treatment of cardiac hypertrophy and heart failure.

Regulators of $\mathrm{G}$ protein signalling (RGS) were originally identified for their ability to accelerate the activity of $\mathrm{G} \alpha$ GTPase, which could reduce the amplitude and duration of GPCR effects. On the basis of target specificity, protein stability, and subcellular localization, the RGS protein superfamily is divided into four subfamilies: R4/B, R7/C, R12/D, and R2/A [13]. To date, at least 20 RGS proteins have been identified in cardiomyocytes and fibroblasts [25, 43, 51, 64, 68]. Previous studies demonstrated that several types of RGS proteins are involved in multiple pathophysiological processes in the heart, such as arrhythmia, heart failure, and hypertension [19, 46, 49, 50, 65, 66]. For example, Klaiber et al. demonstrated that RGS2 was involved in the anti-hypertrophic effects of cardiac atrial natriuretic peptide (ANP) [28].

RGS14, belonging to the R12/D subfamily, is a complex with multi-domain structures. Differing from other RGS, RGS14 contains two G-interacting domains: the RGS domain and the carboxyl terminal GoLoco domain. In addition, a tandem of two Ras-binding domains with affinity for the small GTPases Ras and Rap is located between the RGS and GoLoco domains [57, 58, 69]. It has been reported that RGS14 plays essential roles in cellular mitosis [8, 40, 41], birth process promotion [29], and phagocytosis by activating $\alpha \mathrm{M} \beta 2$ integrin [34]. Studies also revealed a role for RGS14 in suppressing synaptic plasticity in hippocampal CA2 neurons by integrating $G$ protein and the MAPK signalling pathway [30, 61]. However, the exact role of RGS14 in the heart, particularly in response to stress stimuli, has not been investigated, although the expression of RGS14 in heart tissues has been confirmed by many studies $[25,55,68]$. Therefore, it is attractive and meaningful to determine the role and the underlying mechanism of RGS14 in pathological cardiac remodelling. In the present study, we explored if RGS14 expression was altered in hypertrophic hearts and further investigated the crucial role of RGS14 in cardiac remodelling by gain-of-function and loss-of-function approaches. The potential downstream mechanism of RGS14 in cardiac remodelling was well investigated.

\section{Methods and materials}

\section{Reagents}

Foetal calf serum (FCS) was obtained from HyClone (Shanghai, China). The antibodies and their commercial sources are listed below: Cell Signaling Technology (Beverly, MA): U0126 (\#9903), anti-mitogen-activated protein kinase 1/2 (MEK1/2) (\#9122), anti-phosphoMEK1/2 (\#9154), anti-extracellular signal-regulated protein kinase 1/2 (ERK1/2) (\#4695), anti-phospho-ERK1/2 (\#4370), anti-c-Jun N-terminal kinase 1/2 (JNK1/2) (\#9258), anti-phospho-JNK1/2 (\#4668), anti-p38 (\#9212), and anti-phospho-p38 (\#4511); Santa Cruz Biotechnology, Inc.: anti-ANP (\#sc20158) and anti- $\beta$-myosin heavy chain ( $\beta$-MHC) (\#sc53090); Aviva Systems Biology: anti-RGS14 (\#OAAF04168); and Bioworld Technology: anti-GAPDH (\#MB001). The bicinchoninic acid (BCA) protein assay kit was obtained from Pierce (Rockford, IL, USA). All other reagents, including the cell culture reagents, were purchased from Sigma.

\section{Source of human hearts}

The failing human heart samples were obtained from the left ventricle (LV) of dilated cardiomyopathy (DCM) patients after heart transplantation. The control samples were collected from the LV of normal heart donors who died because of an accident. The Institutional Review Board (IRB) of the Third Xiangya Hospital, Central South University approved the study. The relatives of the heart donors signed informed consent.

\section{Mice}

The Animal Care and Use Committee affiliated with the IRB of the Third Xiangya Hospital, Central South University approved all animal experimental protocols. All animals were housed in a light- $(12 \mathrm{~h}$ light $/ 12 \mathrm{~h}$ dark $)$, temperature-controlled environment, and humidity-controlled environment. Food and water were available ad libitum. The animal models used in this study are described below. 


\section{Cardiac-specific RGS14-overexpressing mice}

Full-length mouse RGS14 Complementary DNA (cDNA) (OriGene, MC204443) was ligated into the chicken $\beta$-actin gene (CAG) promoter expression vector, which was linearized and purified using the QIAquick Gel Extraction Kit (Qiagen, 28704). This DNA construct was microinjected into fertilized mouse embryos (C57BL/6J background). Founder transgenic mice were identified by tail DNA amplification and then bred with C57BL/6J mice. Tail genomic DNA was identified using polymerase chain reaction (PCR). The following primers were used for the PCR amplification of the CAG gene promoter: forward, 5'-CCCCCTGAACCTGAAACATA-3'; reverse, 5'-CTGC GCTGAATTCCTTCTTC- $3^{\prime}$. The expected size for the amplification product was $579 \mathrm{bp}$. The RGS14 flox mice were crossed with $\alpha$-MHC-MerCreMer transgenic mice (Jackson Laboratory, 005650) to generate cardiac-specific RGS14-TG mice. Four independent transgenic lines were established. To induce RGS14 expression specifically in the heart, 6-week-old double transgenic mice were injected intraperitoneally with tamoxifen $(80 \mathrm{mg} / \mathrm{kg}$ per day; Sigma, T-5648) for 5 consecutive days to cause Cre-mediated CAT gene excision. CAG-CAT-RGS14/MHC-Cre mice without tamoxifen administration (CRMC) served as the control group.

\section{Generation of RGS14 knockout mice}

Directive sequences of the target site for the RGS14 gene in the mouse were predicted by the online CRISPR design system (http://crispr.mit.edu) (Fig. 3a). A pair of oligomers (oligo1, TAGGGGCCTGGGAACCTGCAGTGC; oligo2, AAACGCACTGCAGGTTCCCAGGCC) was cloned into the BsaI restriction site of the pUC57-single guide RNA (sgRNA) expression vector (Addgene, 51132). DNA was amplified by PCR with primers spanning the T7 promoter and sgRNA regions (forward primer, GATCCCTAATA CGACTCACTATAG; reverse primer, AAAAAAAGCAC CGACTCGGT). The sgRNA was transcribed by the MEGAshortscript kit (Ambion, AM1354) and purified by the miRNeasy Micro kit (Qiagen, 217084). The Cas9 expression plasmid (Addgene 44758) was linearized with PmeI and used as the template for in vitro transcription using the T7 Ultra Kit (Ambion, AM1345). Cas9 and sgRNA mRNA injections of single-cell embryos were performed by the FemtoJet 5247 microinjection system. Genomic DNA was extracted, and a 405 bp DNA fragment overlapping the sgRNA target site was amplified by PCR with the following primers: RGS14-F, $5^{\prime}$-CTGTGTGGAC ACTCCCATCC- $3^{\prime}$; and RGS14-R, 5'-ACCACAGAGAGA AGCAGCAC- $3^{\prime}$. The purified PCR product was denatured and reannealed in NEB Buffer 2 to form heteroduplex
DNA that was digested with T7EN (NEB, M0302L) for $45 \mathrm{~min}$ and analyzed by $3.0 \%$ agarose gel (Fig. $3 \mathrm{~b}$ ). These mice were sequenced to select for frameshift mutations (Fig. 3c). The following primers were used to screen F1 and F2 offspring: RGS14-F, 5'-CTGTGTGGACA CTCCCATCC- $3^{\prime}$; and RGS14-R, 5'-ACCACAGAGAG AAGCAGCAC- $3^{\prime}$. Finally, RGS14 knockout (RGS14-KO or $R G S 14^{-1-}$ ) mice were generated and identified as shown in Fig. 3d, e. Littermate controls of the RGS14-KO mice were wild-type mice (WT or $R G S 14^{+/+}$).

\section{Cardiac-specific CaMEK1-TG and CaMEK1/RGS14 double TG mice}

To obtain CaMEK1 flox mice, the coding sequence of mouse MEK1 S218D/S222D cDNA was ligated into the CAG promoter expression vector. This DNA construct was microinjected into fertilized mouse embryos (C57BL/6J background), and the resulting TG mice were PCR-genotyped using tail genomic DNA and the following primers: forward, 5'-CCCCCTGAACCTGAAACATA-3'; and reverse, $5^{\prime}$-CTGCGCTGAATTCCTTCTTC- $3^{\prime}$. The expected size for the amplification product was $515 \mathrm{bp}$. The CaMEK1 flox mice were crossed with $\alpha-M H C-M e r$ CreMer transgenic mice, which were obtained from the Jackson Laboratory (No. 005650), to generate CAG-MEK1/ MHC-Cre mice. Tamoxifen $(80 \mathrm{mg} / \mathrm{kg}$ per day; Sigma, T-5648) was then injected into the CAG-MEK1/MHC-Cre mice containing the $C a M E K 1$ gene at 6 weeks of age for 5 consecutive days. CAG-MEK1/MHC-Cre mice without tamoxifen administration (CMMC) served as the control group. Finally, the CRMC mice were crossed with the CMMC mice and treated with tamoxifen to generate CaMEK1/RGS14 double transgenic (DTG) mice.

\section{Aortic banding surgery}

Aortic banding ( $\mathrm{AB}$ ) was performed as described previously [22, 37]. Briefly, mice were anesthetized using an intraperitoneal injection of sodium pentobarbital $(50 \mathrm{mg} /$ $\mathrm{kg}$, Sigma) and ventilated with room air using a small animal ventilator (model VFA-23-BV, Kent Scientific, USA). The mice were kept warm on a heating pad until they regained consciousness. The left chest was opened after blunt dissection at the second intercostal space, and the thoracic aorta was identified. We tied the thoracic aorta to a $27 \mathrm{G}$ or $26 \mathrm{G}$ needle with a 7-0 silk suture depending on the body weight. The needle was removed quickly after the ligation, and the thoracic cavity was closed. Finally, the adequacy of aortic constriction was determined by the Doppler analysis. The mice in the control group were subjected to the same procedure without ligation of the aorta. 


\section{Echocardiography evaluation}

After the indicated times, the surviving mice were anesthetized using 1.5-2 \% isoflurane and then subjected to echocardiography to examine cardiac function and structure, as previously described [21]. Briefly, a Mylab30CV ultrasound system switched to M-mode tracings with a $15 \mathrm{MHz}$ probe was used to determine echocardiography. The LV end-diastolic dimension (LVEDd), LV end-systolic dimension (LVESd), and LV fractional shortening [FS $(\%)=($ LVEDd-LVESd $) /$ LVEDd $\times 100 \%]$ were measured from the short axis of the LV at the level of the papillary muscles.

\section{Histological analysis and immunofluorescence staining}

The animals were sacrificed 4-8 weeks after the $A B$ or sham surgery. The hearts were harvested, arrested in diastole with $10 \%$ potassium chloride solution, fixed with $10 \%$ formalin, dehydrated, and embedded in paraffin. Paraffin-embedded hearts were cut transversely into 4-5 $\mu \mathrm{m}$ sections. Sections at the mid-papillary muscle level were stained with hematoxylin and eosin $(\mathrm{H} \& \mathrm{E})$ and picrosirius red (PSR) to calculate the cardiomyocyte crosssectional area (CSA) and collagen deposition volume, respectively. Fluorescein isothiocyanate-conjugated wheat germ agglutinin (WGA) was used to visualize the size of the cardiomyocytes. The immunofluorescence analysis was performed using the standard immunocytochemical techniques. Cardiomyocyte CSA, interstitial collagen deposition and perivascular collagen deposition were measured using the Image-Pro Plus 6.0 software.

\section{Quantitative real-time PCR and western blotting}

Total mRNA was isolated from heart tissues or neonatal rat cardiomyocytes (NRCMs) using TRIzol reagent (Invitrogen). cDNA, which was obtained by reverse transcription of RNA, was synthesized using the Transcriptor First Strand cDNA Synthesis kit (Roche). Quantitative real-time PCR was performed using SYBR Green (Roche), and the relative expression of the target genes was calculated. GAPDH was measured and used for normalization. Cardiac tissue and cultured cardiomyocytes were lysed in RIPA lysis buffer, and the protein concentration was determined with a BCA protein assay kit. The proteins $(50 \mu \mathrm{g})$ were resolved via SDS-PAGE (Invitrogen) and transferred to a PVDF membrane (Millipore), which was then subsequently blocked with milk. After overnight incubation with the indicated primary antibodies at $4{ }^{\circ} \mathrm{C}$, the membranes were washed at least three times and then incubated with a secondary antibody for $1 \mathrm{~h}$ at room temperature. Finally, enhanced chemiluminescence-treated membranes were visualized using a FluorChem E imager (ProteinSimple, FluorChem E). The results were normalized to GAPDH.

\section{Cardiomyocyte and cardiac fibroblast culture and infection with recombinant adenoviral vectors}

The heart ventricles of 1- to 2-day-old Sprague-Dawley rats were enzymatically dissociated into individual cardiomyocytes in PBS containing $0.03 \%$ trypsin and $0.04 \%$ type II collagenase. Fibroblasts were then removed by a differential attachment technique, and the NRCMs were plated at a density of $1 \times 10^{6}$ cells/well in six-well plates and cultivated in DMEM/F12 medium containing $20 \%$ FCS, penicillin/streptomycin, and bromodeoxyuridine to inhibit fibroblast proliferation. The cardiomyocytes were maintained in serum-free DMEM/F12 for $12 \mathrm{~h}$ and then treated with angiotensin II (Ang II, $1 \mu \mathrm{M}$ ) for 24 or $48 \mathrm{~h}$ to induce hypertrophy.

To obtain cardiac fibroblasts, the adherent non-myocyte fractions obtained during pre-plating were grown in DMEM containing $10 \%$ FCS to confluence and passaged with trypsin-EDTA. All experiments were performed on cells from the first or second passages. Cardiac fibroblasts were placed in DMEM medium containing $0.1 \%$ FCS for $24 \mathrm{~h}$ before the stimulation by Ang II for $24 \mathrm{~h}$, and the expression of RGS14 was investigated.

Finally, cardiomyocytes were infected with adenoviral RGS14 (AdRGS14) to overexpress RGS14, and an adenoviral vector encoding the green fluorescent protein gene (AdGFP) was infected into cardiomyocytes as a control group. Adenoviral short hairpin RGS14 (AdshRGS14) constructs were obtained and infected into cardiomyocytes to knockdown RGS14 expression, and an adenoviral short hairpin RNA (AdshRNA) was used as the non-targeting control. NRCMs were infected with different adenoviruses in diluted medium for $12 \mathrm{~h}$.

\section{Treatment of mice with U0126}

U0126, an inhibitor of MEK1/2, was dissolved in dimethyl sulfoxide (DMSO) at a volume of $1 \mathrm{ml}$ per $100 \mathrm{~g}$ of body weight and it was injected intraperitoneally into mice every 3 days $(1 \mathrm{mg} / \mathrm{kg})$ after AB. The control group was injected with a similar volume of DMSO.

\section{Statistical analysis}

The results are expressed as the mean \pm standard deviation (SD). All data were analyzed using Student's two-tailed $t$ test and analysis of variance (ANOVA) to compare the means of two groups of samples and multiple groups, 
respectively. The $T$ approximation test was used for the analysis when the sample was less than 7. All statistical analyses were performed with the SPSS software (version 17.0). $P<0.05$ was considered statistically significant.

\section{Results}

\section{RGS14 expression is decreased in hypertrophic hearts}

To investigate if the expression of RGS14 was altered during the process of pathological remodelling, we first measured RGS14 expression in human failing hearts, murine hypertrophic hearts, and NRCMs. According to the western blotting results, the RGS14 protein levels in human failing hearts were reduced to approximately $40 \%$ of the levels in normal donor hearts. This decrease was accompanied by an enhancement of the foetal gene profile of ANP and $\beta$-MHC (Fig. 1a). Similar results were found in murine hypertrophic hearts and NRCMs. As shown in Fig. 1b, the expression levels of RGS14 were approximately two-fold and four-fold lower in the experimental mouse hearts after 4 or 8 weeks of $\mathrm{AB}$, respectively, compared with the sham-operated control group. In addition, the expression levels of ANP and $\beta$-MHC were dramatically increased at week 4 and more pronounced at week 8 (Fig. 1b). Furthermore, stimulation of NRCMs with Ang II $(1 \mu \mathrm{mol} / \mathrm{L})$ for 24 or $48 \mathrm{~h}$ led to RGS14 downregulation and $\beta$-MHC and ANP up-regulation (Fig. 1c). The expression of RGS14 was not significantly changed in response to AngII stimulation for $24 \mathrm{~h}$ in the isolated cardiac fibroblasts (Figure S1). These results indicated that RGS14 in cardiomyocytes was markedly altered by hypertrophic stress in vivo and in vitro, which demonstrated that RGS14 might be involved in cardiac remodelling.

\section{RGS14 protects against angiotensin II-induced cardiomyocyte hypertrophy in vitro}

To explore the functional contribution of RGS14 to the hypertrophy of cardiomyocytes in vitro, we first performed studies using primary cultured NRCMs infected with AdshRGS14, AdRGS14, or control vectors, and further stimulated with Ang II $(1 \mu \mathrm{mol} / \mathrm{L})$ for $48 \mathrm{~h}$. The protein expression of RGS14 is shown in Fig. 2a and S2A. Immunostaining with the $\alpha$-actin antibody suggested that neither the NRCMs infected with AdRGS14 nor the NRCMs infected with AdshRGS14 exhibited altered cell
Fig. 1 RGS14 is downregulated in the failing heart and in the experimental hypertrophic models. a Western blot analysis of ANP, $\beta$-MHC, and RGS14 protein expression in normal donor hearts and failing hearts from patients with dilated cardiomyopathy $(n=4$ per group, $* P<0.05$ vs. normal donor heart). b Western blot analysis of ANP, $\beta$-MHC, and RGS14 protein expression in hypertrophic hearts from experimental mice undergoing $\mathrm{AB}(n=4$ mice per group, $* P<0.05$ vs. sham). $\mathbf{c}$ Western blot analysis of ANP, $\beta$-MHC, and RGS14 in cultured neonatal rat cardiomyocytes stimulated by Angiotensin II $(1 \mu \mathrm{mol} / \mathrm{L}$; $n=4$ ) for 24 or $48 \mathrm{~h}$

$(* P<0.05$ vs. PBS). Left Representative western blot. Right Bar graphs: quantitative results. $n$ indicates the number of independent experiments.

The data are presented as the mean $\pm \mathrm{SD}$
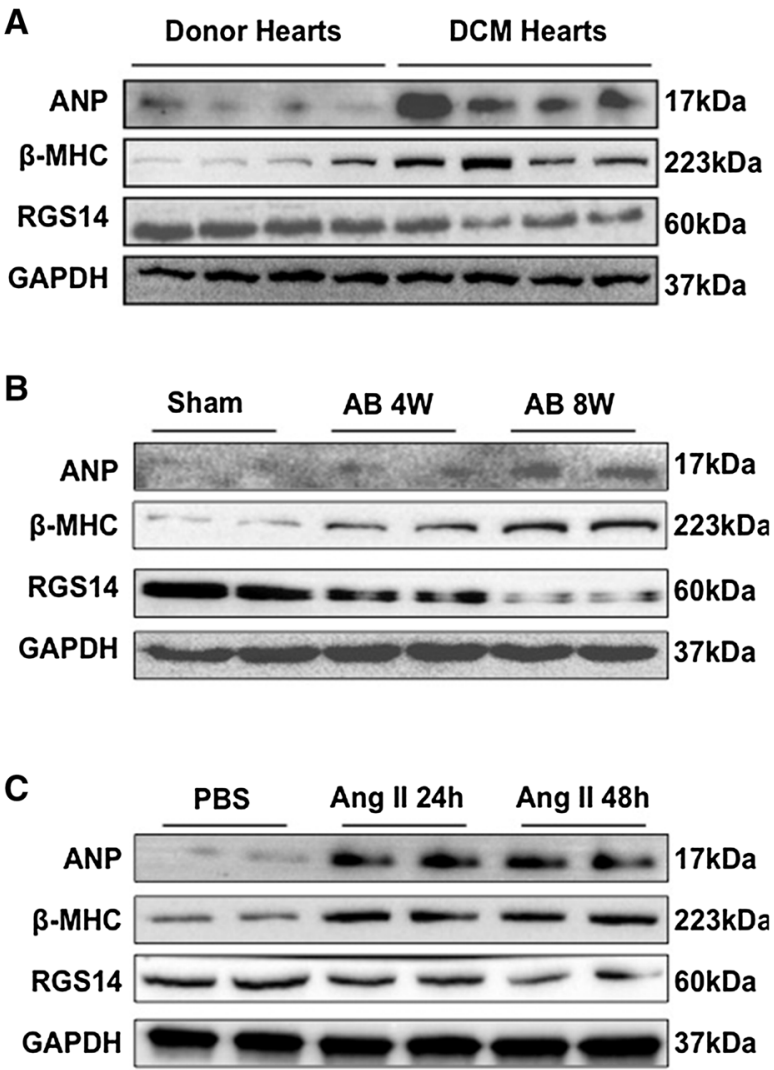

size compared with the NRCMs infected with AdGFP or AdshRNA under basal conditions. However, AdshRGS14 treatment enhanced the Ang II-induced increase in cell size (Fig. 2b, c). Furthermore, the mRNA levels of ANP and $\beta$ MHC were approximately 1.5 - and 2.4-fold higher, respectively, in the NRCMs infected with AdshRGS14 after exposure to Ang II than in the controls (Fig. 2e). The cells with overexpression of RGS14 (AdRGS14) exhibited significantly reduced cell-surface areas (approximately $40 \%$ ) compared with the AdGFP-infected cells, and the mRNA expression of ANP and $\beta$-MHC was significantly decreased (approximately 25\%) in AdRGS14-infected cells compared with the cells infected with AdGFP (Fig. 2b, d, f). Together, these observations indicate that RGS14 protected against the hypertrophic response in cardiomyocytes.

\section{Ablation of RGS14 exacerbates pressure overload- induced remodelling}

The potential function of RGS14 during cardiac remodelling in vivo was investigated. RGS14-KO mice were generated using the CRISPR/Cas9 methods (Fig. 3a-c). Gene sequencing and western blotting of RGS14 expression in heart tissue from RGS14-KO and littermate control mice were performed (Fig. 3d, e). At baseline, the RGS14KO mice displayed normal cardiac morphology and contractile function (Table S1). The levels of RGS2, 3, 4, and 5 were not significantly changed in the RGS14-KO mice compared with the WT mice (Figure S3). As shown in Fig. $4 \mathrm{a}$, aortic banding induced a $58 \%$ increase in the ratio of heart weight to body weight (HW/BW), indicating the development of cardiac hypertrophy in wild-type mice. The RGS $14^{-1-}$ mice exhibited a significantly aggravated hypertrophic effect with an increase of approximately $27 \%$ in the ratio of $\mathrm{HW} / \mathrm{BW}$ compared with the WT mice subjected to AB surgery. Similar effects were observed in the ratio of lung weight to body weight ( $\mathrm{LW} / \mathrm{BW})$ and in the ratio of heart weight to tibia length (HW/TL) (Fig. 4b, c). No comparable differences were observed in the shamtreated $\mathrm{RGSI}^{-1-}$ and the WT mice (Fig. 4a-c). Cardiac function was also measured by echocardiography. The parameters of LVEDd, LVESd, and FS\% indicated that myocardial contraction in the AB-treated $R G S 14^{-1-}$ mice was reduced compared with the WT group subjected to AB (Fig. 4d-f). H\&E and WGA staining showed a greater ventricular CSA in the RGS14 ${ }^{-1-}$ mice than in the control mice subjected to AB surgery (Fig. 4g, h). Because fibrosis is a classical feature of pathological cardiac remodelling and is characterized by the accumulation of collagen in the heart [48], we evaluated the effects of RGS14 deletion on cardiac fibrosis in pressure-overloaded hearts. Fibrosis was determined by visualizing the extent of collagen staining
Fig. 2 RGS14 protects against Ang II-induced cardiomyocyte hypertrophy in vitro. a RGS14 protein expression in NRCMs infected with AdRGS14, AdshRGS14, or respective controls (AdGFP or AdshRNA). b Representative anti- $\alpha$-actin antibody staining images of NRCMs infected with AdRGS14, AdshRGS14, or respective controls in response to PBS and Ang II $(1 \mu \mathrm{mol} / \mathrm{L})$ treatment for $48 \mathrm{~h}$ (blue nucleus, green $\alpha$-actinin, scale bar $20 \mu \mathrm{m}$ ). c Quantitative results of the CSA of NRCMs infected with AdshRGS14 compared with AdshRNA in response to PBS and Ang II $(n>40$ cells per group, ${ }^{*} P<0.05$ vs. AdshRNA/PBS; ${ }^{\#} P<0.05$ vs. AdshRNA/Ang II). d Quantitative results of the CSA of NRCMs infected with AdRGS14 compared with AdGFP in response to PBS and Ang II ( $n>40$ cells per group, $* P<0.05$ vs. AdGFP/PBS; ${ }^{\#} P<0.05$ vs. AdGFP/Ang II). e Real-time PCR evaluation of the mRNA levels of ANP and BNP in PBS- and Ang II-treated NRCMs infected with AdshRGS14 or AdshRNA $(n=4, * P<0.05$ vs. AdshRNA/PBS; ${ }^{\#} P<0.05$ vs. AdshRNA/Ang II). f Real-time PCR evaluation of the mRNA levels of ANP and $\beta$-MHC in PBS- and Ang II-treated NRCMs infected with AdRGS14 or $\operatorname{AdGFP}(n=4, * P<0.05$ vs. AdGFP/PBS; ${ }^{\#} P<0.05$ vs. AdGFP/Ang II). The data are presented as the mean $\pm \mathrm{SD}$

and calculating the total collagen volume. Both perivascular and interstitial fibrosis analyses consistently demonstrated an increased fibrotic response in the AB-treated $R G S 14^{-1-}$ mice compared with the AB-treated WT mice (Fig. 4g, i). We measured the synthesis of collagen by analyzing the mRNA expression of hypertrophic markers (ANP, BNP, and $\beta$-MHC) and fibrotic markers (collagen I, collagen III, and fibronectin) (Fig. 4j). Our results consistently revealed an increased fibrotic response in $\mathrm{RSSI}^{-1-}$ hearts. Collectively, these findings reveal that ablation of RGS14 exacerbates hypertrophy and fibrosis in response to chronic pressure overload.

\section{Overexpression of RGS14 attenuates pressure overload-induced cardiac remodelling}

To further confirm the protective effect of RGS14 on cardiac remodelling, cardiac-specific transgenic mice overexpressing murine RGS14 under the control of the CAG promoter were generated, and four independent RGS14-TG mice were generated (Fig. 5a). Cardiac RGS14 expression in these TG mice was approximately two- to eight-fold higher than that in their CRMC littermates. TG line 2, carrying the highest levels of RGS14 expression, was selected for further research. At baseline, the RGS14-TG2 mice displayed normal cardiac morphology and contractile function (Table S1). The levels of RGS2, 3, 4, and 5 were not significantly changed in the RGS14-TG2 mice compared with the CRMC mice (Figure S3). A morphological disparity occurred when comparing RGS14-TG2 to CRMC mice 4 weeks after AB. As shown in Fig. 5b, AB induced a $40 \%$ increase in the HW/BW compared with the sham control, suggesting the development of cardiac hypertrophy 



B

Neonatal Rat Cardiomyocytes (48 hours)
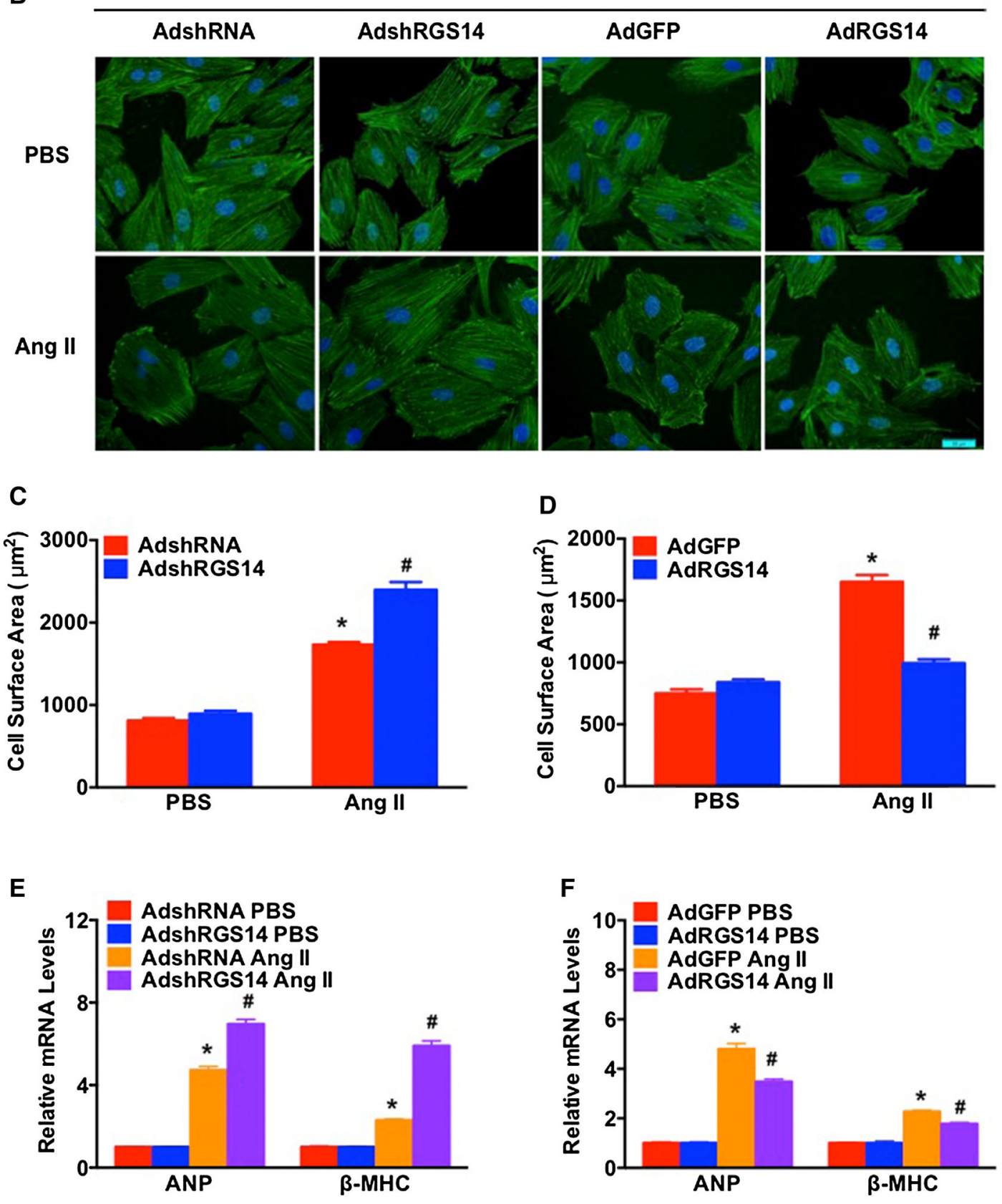
A
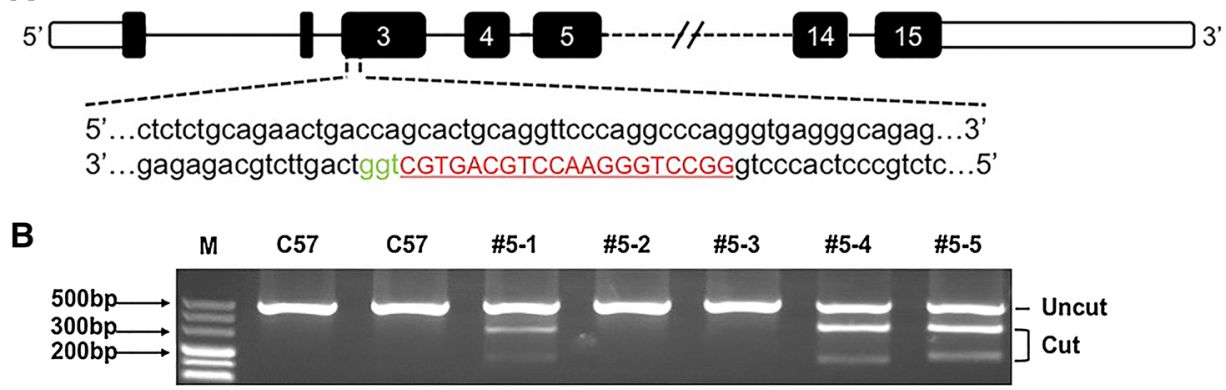

C

PAM sgRNA binding site

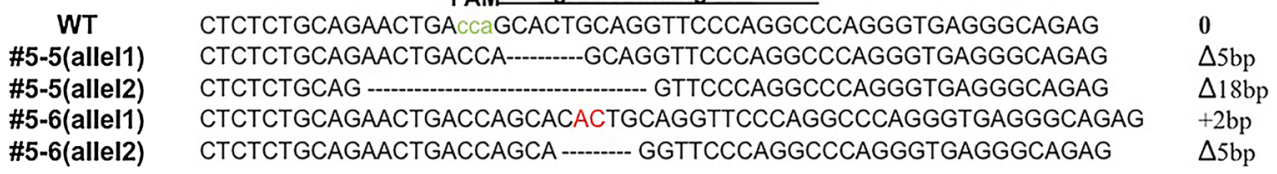

D

wT CTGCAGAACTGACCAGCACTGCAGGTTCCCAGGCC CT GCA GAACT GAC CA G CA GGT T CCCA G GC CCAGGG

ко

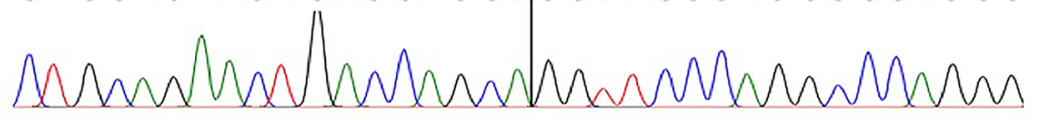

E

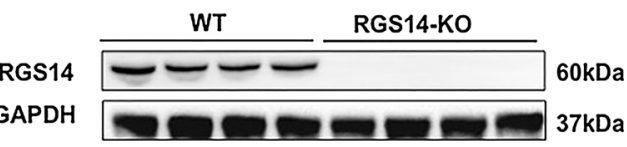

Fig. 3 Schematic diagram of the construction of RGS14-KO mice using the CRISPR-Cas9 method and identification of RGS14 expression. a One sgRNA targeting a region downstream of the $3^{\prime}$ end of exon 3 in the RGS14 mouse gene was designed and constructed. b After microinjection, a T7E1 assay indicated that four out of six pups contained cleavage products, suggesting a mixture of mutant and wild-type DNA templates in these mice. c Following subcloning of the PCR products, eight subclones of each mouse were

in the CRMC mice, whereas the TG2 mice exhibited a significant protective effect against hypertrophy, with a decrease of $23 \%$ in the HW/BW. A similar protective effect against hypertrophy was observed in the LW/BW and HW/TL. In contrast to the CRMC mice, the TG2 mice exhibited significant decreases in the LW/BW and HW/TL (Fig. 5c, d). These changes were consistent with the protective role of RGS14 in cardiac function in response to hypertrophic stimulation, as measured by cardiac function parameters (LVEDd, LVESd and FS\%) by echocardiography (Fig. $5 \mathrm{e}-\mathrm{g}$ ). Compared with the CRMC mice, the RGS14-TG2 mice had smaller heart and cardiomyocyte sizes (Fig. 5h, i) and reduced fibrosis volumes (Fig. 5h, j). Furthermore, $\mathrm{AB}$ increased the mRNA levels of ANP, BNP, $\beta$-MHC, collagen I, collagen III, and fibronectin in the hearts of the CRMC mice, and these expression levels were significantly suppressed in the RGS14-TG2 mice (Fig. 5k). We also examined the hypertrophic response of RGS14-TG1 mice (RGS14 expression is 2.5-fold higher sequenced. All of the subclones carried a single mutant allele, whereas two indels (\#5-5, \#5-6) produced frameshift mutations. Founder \#5-5 was mated to a C57BL/6J mouse to obtain the F1 generation. d Gene sequencing for RGS14 expression levels in hearts from wild-type and RGS14 knockout groups. e Representative western blots for RGS14 expression levels in hearts from the $R G S 14^{+/+}$and $R G S 14^{-/-}$groups

than that of CRMC) to evaluate the relevance of RGS14 expression in cardiac hypertrophy. As shown in Figure S4, the heart weight/body weight ratio and the cross-sectional

Fig. 4 RGS14 ablation exacerbates pressure overload-induced cardiac hypertrophy. a-c The HW/BW, LW/BW, and HW/TL ratios were measured in $R G S 14^{+/+}$and $R G S 14^{-/-}$mice 4 weeks after sham or AB treatment, $n=12-13$ for each group. d-f Echocardiographic parameters (LVEDd, LVESd, and FS\%) for $R G S 14^{+/+}$or $R G S 14^{-/-}$ mice after sham treatment and $\mathrm{AB}$ treatment ( $n=4-7$ per group). g Sections of hearts from $R G S 14^{+/+}$and $R G S 14^{-1-}$ mice subjected to $\mathrm{AB}$ or sham treatment were stained with $\mathrm{H} \& \mathrm{E}$ (first row: scale bar $50 \mu \mathrm{m}$ ), WGA (second row: scale bar $50 \mu \mathrm{m}$ ), and PSR (third row and fourth row: scale bars $50 \mu \mathrm{m}$ ) to analyze cardiac hypertrophy and fibrosis ( $n=5$ per group). h Quantification of cardiomyocyte crosssectional area in sham-treated and AB-treated $R G S 14^{+/+}$or $R G S 14^{-1-}$ mice ( $n=5$ per group). i Quantification of fibrosis areas in sham-treated and AB-treated RGS14 ${ }^{+/+}$or $R G S 14^{-1-}$ mice $(n=5$ per group). $\mathbf{j}$ mRNA levels of hypertrophic and fibrotic markers in the hearts of $R G S 14^{+/+}$and $R G S 14^{-l-}$ mice subjected to sham treatment or $\mathrm{AB}$ treatment ( $n=4$ per group). The data are presented as the mean \pm SD. ${ }^{*} P<0.05$ vs. WT/sham. ${ }^{\#} P<0.05$ vs. WT/AB 

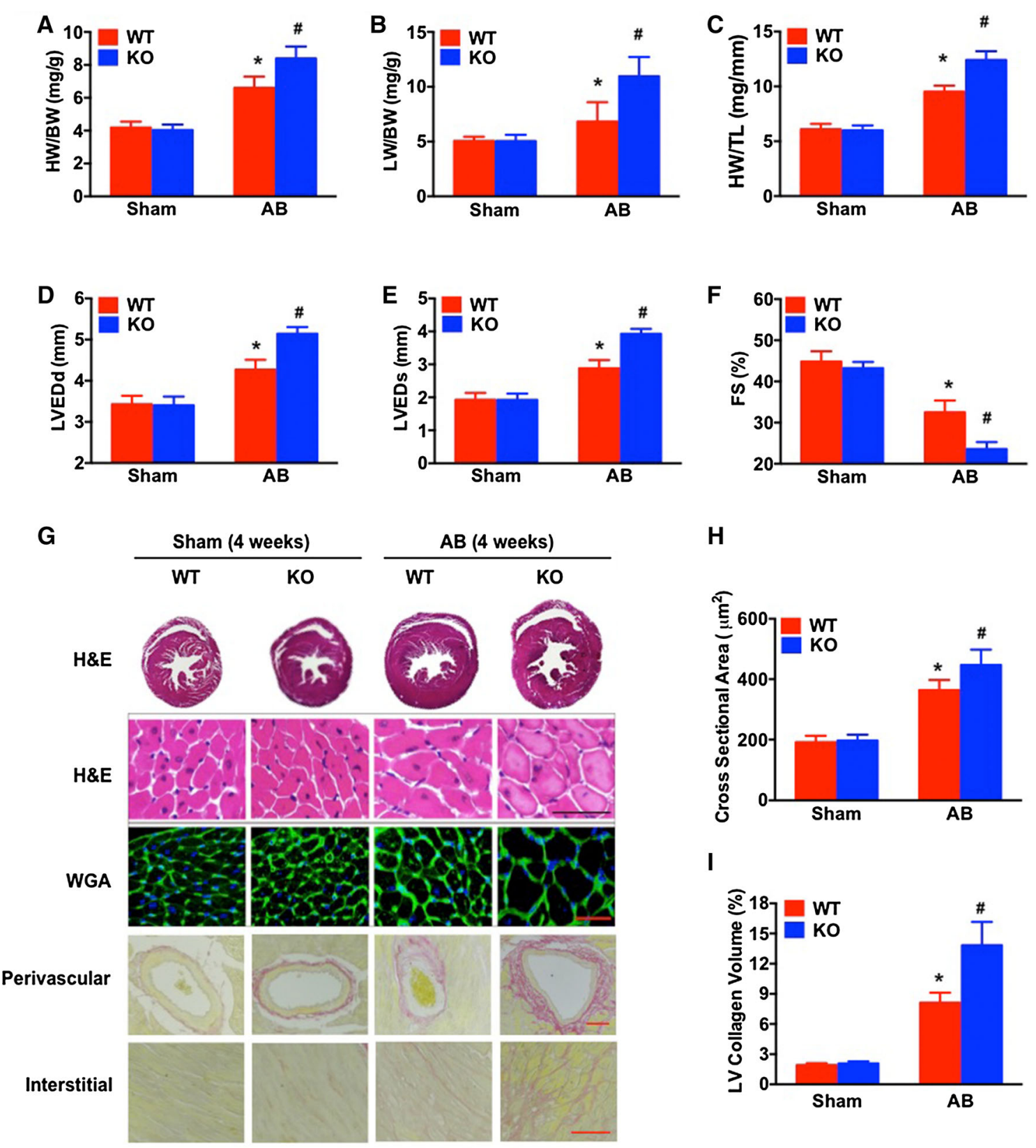

H

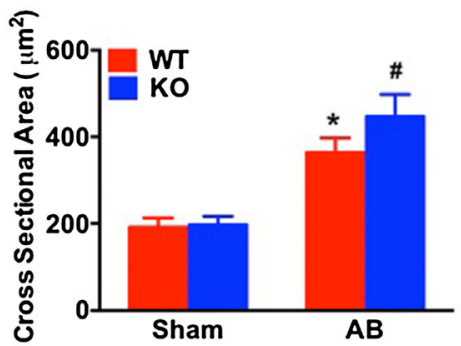

I
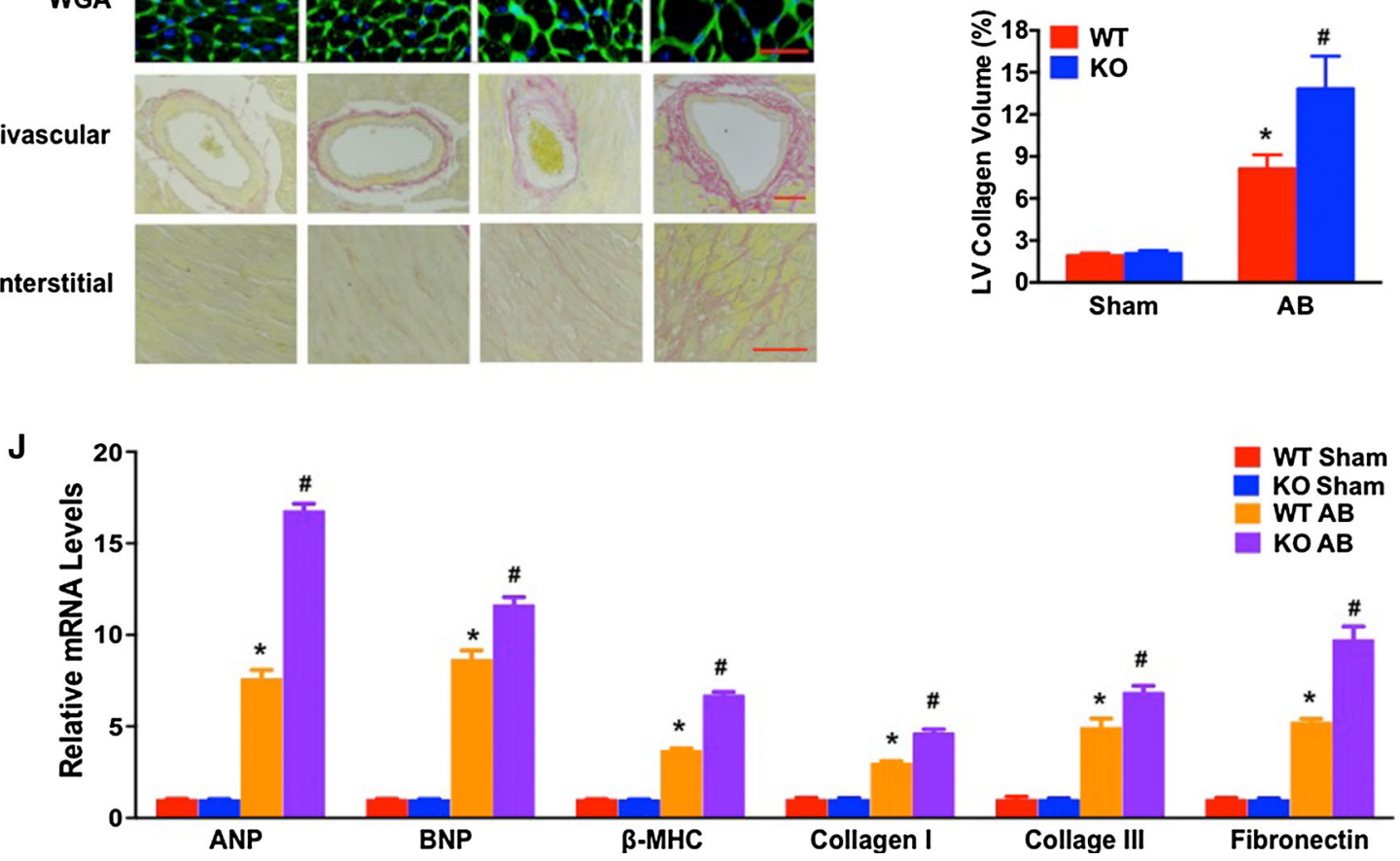
area were slightly, but significantly reduced in the RGS14TG1 group compared with the CRMC controls, 4 weeks after AB surgery. The protective effect of RGS14 on pressure overload-induced cardiac hypertrophy in the RGS14-TG1 mice was significantly weaker than in the RGS14-TG2 mice, suggesting a possible gene doses effect. Together, these results indicate that overexpression of RGS14 might suppress cardiac remodelling induced by AB in vivo.

\section{RGS14 suppresses cardiac remodelling via the MEK-ERK1/2 signalling pathway}

To determine the underlying mechanism of the anti-hypertrophy effect of RGS14, the expression and activity of MAPK signalling molecules were detected. RGS14-TG2 mice were selected for the current research. As shown in Fig. 6a, b, the phosphorylation levels of MEK1/2, ERK1/2, JNK1/2, and p38 were significantly elevated after AB surgery, whereas the total protein expression remained unchanged. Deletion of RGS14 further increased the activation of MEK1/2 and ERK1/2 by 1.6- and 2.6-fold, respectively, compared with the WT mouse hearts subjected to AB. Overexpression of RGS14 restored the phosphorylation level of MEK1/2 and ERK1/2 to approximately normal. Neither p38 nor JNK phosphorylation was altered in the AB-induced $R G S 14^{-1-}$ and RGS14-TG hearts.

To exclude potential compensatory mechanisms in vivo, further NRCM experiments were conducted. AdshRGS14 and AdRGS14 were used to knock down or overexpress RGS14 expression in NRCMs, respectively. The protein expression of RGS14 in different groups is shown in Figure S2. The expression and activity of MAPK signalling molecules were detected compared with AdshRNA and AdGFP controls. Western blot analysis showed that RGS14 down-regulation enhanced the expression of phosphorylated MEK1/2 and ERK1/2 compared with AdshRNA-infected cells under Ang II treatment (Fig. 6c), whereas RGS14 up-regulation strongly suppressed the levels of MEK1/2 and ERK1/2 phosphorylation in AdRGS14-infected NRCMs compared with the AdGFP-infected group (Fig. 6d). Our results demonstrate that the RGS14-elicited anti-hypertrophic effect is largely associated with the inhibition of MEK-ERK1/2 signalling in hearts.

To determine if the MEK-ERK1/2 pathway plays an essential role in RGS14-induced protection in AB-induced cardiac hypertrophy, U0126 (an inhibitor of MEK) was infused into WT and RGS14-KO mice before AB surgery. Western blot analysis indicated lower levels of phosphorylated MEK1/2 and ERK1/2 in U0126-treated RGS14-KO mice compared with control mice (Fig. 7a). As shown in Fig. 7b-j, U0126 significantly restricted the deteriorative
Fig. 5 RGS14-TG mice are protected from AB-induced cardiac hypertrophy. a A schematic diagram of the generation of TG mice with cardiac-specific expression of RGS14 is shown on the left. Representative western blots for RGS14 expression levels in hearts from TG and CRMC mice are shown on the right. b-d The HW/BW, $\mathrm{LW} / \mathrm{BW}$, and HW/TL ratios in TG2 and CRMC mice after sham treatment or $\mathrm{AB}$ treatment for 4 weeks ( $n=12-13$ for each group). e-g Cardiac function (LVEDd, LVESd and FS) measured by echocardiography for TG2 or CRMC mice after sham treatment and $\mathrm{AB}$ treatment $(n=6-7$ per group). h Sections of hearts from TG2 and $\mathrm{CRMC}$ mice subjected to $\mathrm{AB}$ or sham treatment were stained with H\&E (first row: scale bar $50 \mu \mathrm{m}$ ), WGA (second row: scale bar $50 \mu \mathrm{m}$ ), and PSR (third and fourth row: scale bars $50 \mu \mathrm{m}$ ) to analyze cardiac hypertrophy and fibrosis ( $n=5$ per group). i Quantification of cardiomyocyte CSA in sham-treated and AB-treated TG2 and CRMC mice ( $n=5$ per group). $\mathbf{j}$ Quantification of fibrosis areas in sham-treated and $\mathrm{AB}$-treated TG2 and CRMC mice $(n=5$ per group). $\mathbf{k}$ mRNA levels of hypertrophic and fibrotic markers in the hearts of TG2 and CRMC mice subjected to sham treatment or AB treatment ( $n=4$ per group). The data are presented as the mean $\pm \mathrm{SD}$. ${ }^{*} P<0.05$ vs. CRMC/sham. ${ }^{\#} P<0.05$ vs. CRMC/AB

cardiac remodelling in $R G S 14-\mathrm{KO}$ mice in response to $\mathrm{AB}$. In U0126-treated RGS14-KO mice, the HW/BW, LW/BW, and HW/TL ratios were decreased compared with the DMSO-control group (Fig. 7b-d), and heart function according to LVEDd, LVESd, and FS\% values was improved compared with the DMSO-control group (Fig. 7e-g). Moreover, smaller cross-sectional areas of cardiomyocytes (Fig. 7h, i) and lower collagen volumes (Fig. 7h, j) were observed in the RGS14-KO mice treated with U0126 compared with the DMSO-treated controls. These parameters were equal in both the U0126-treated RGS14-KO mice and the WT mice (Fig. 7b-j). These findings suggest that pre-inhibition of MEK-ERK1/2 signalling protects against $\mathrm{AB}$-induced cardiac remodelling in RGS14-KO mice.

Transgenic mice with floxed CaMEK1 were crossed with transgenic $\alpha M H C$-MerCre-Mer mice to generate cardiac-specific CaMEK1 transgenic mice (CaMEK1-TG), and transgenes were identified by the western blot analysis (Fig. 8a, b). The level of MEK was significantly increased in the CaMEK1-TG mice compared with the CMMC group. RGS14/CaMEK1 DTG mice were generated by crossing CRMC mice with CMMC mice and treating the mice with tamoxifen (Fig. 8c). At baseline, the CaMEK1TG and DTG mice displayed normal cardiac morphology and contractile function (Table S1). The RGS14 and phospho-ERK levels were determined in the CaMEK1/ RGS14 DTG mice, as shown in Figure S5. As expected, the overexpression of CaMEK1 produced more AB-induced cardiac remodelling compared with the CRMC group (Fig. 8d-1). Four weeks after AB surgery, the HW/BW, LW/BW, and HW/TL ratios were significantly increased in the DTG group compared with the RGS14-TG group (Fig. 8d-f). In addition, the LVEDd, LVESd, and FS\% 
A

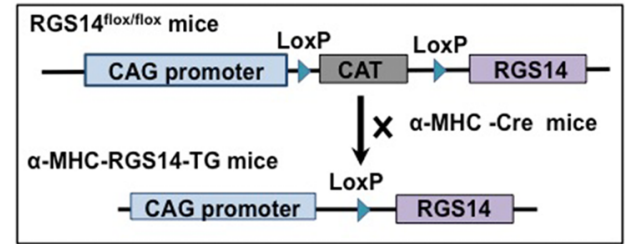

\section{B}

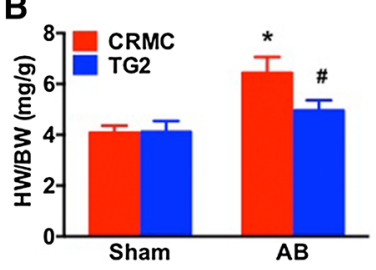

E

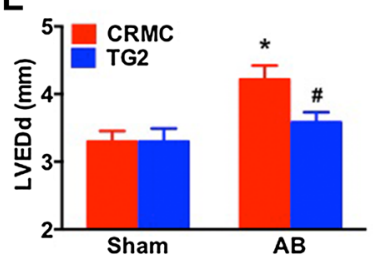

C

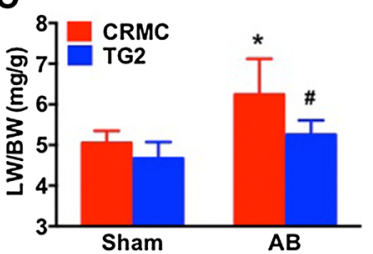

$\mathbf{F}$

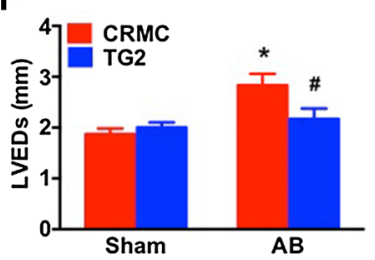

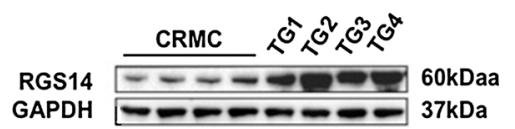

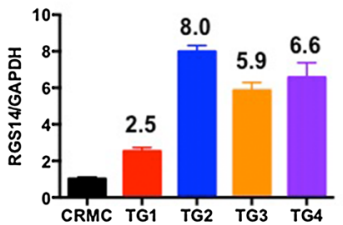

D

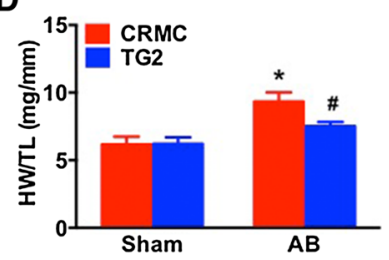

G

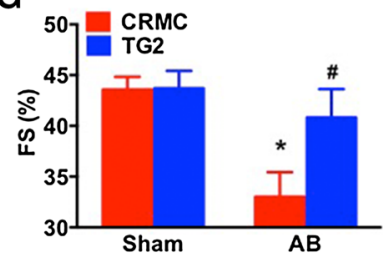

I

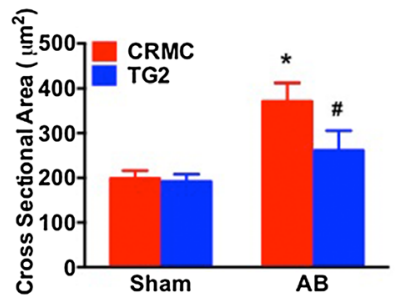

J

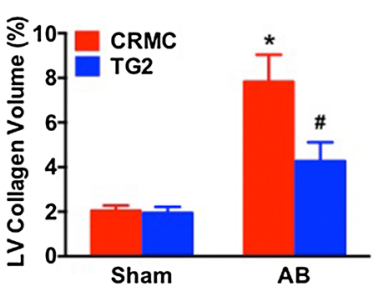

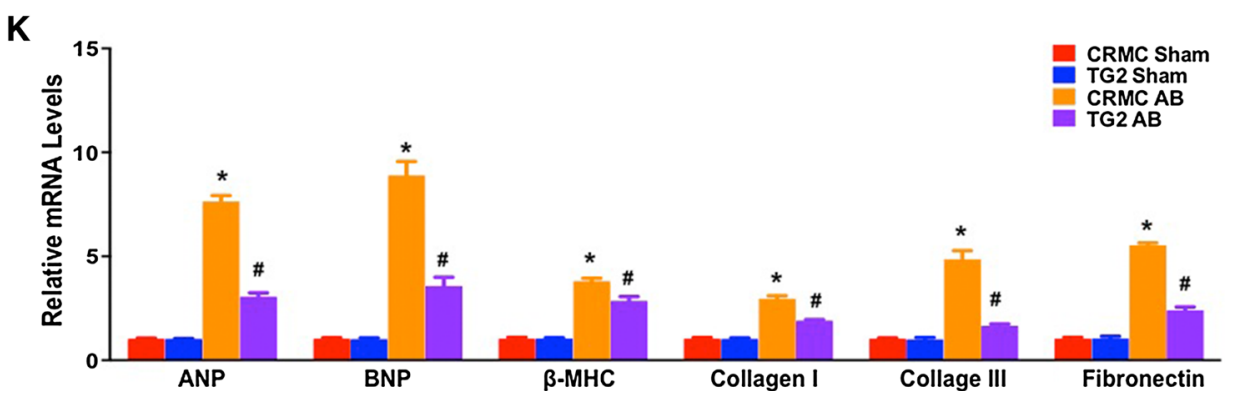



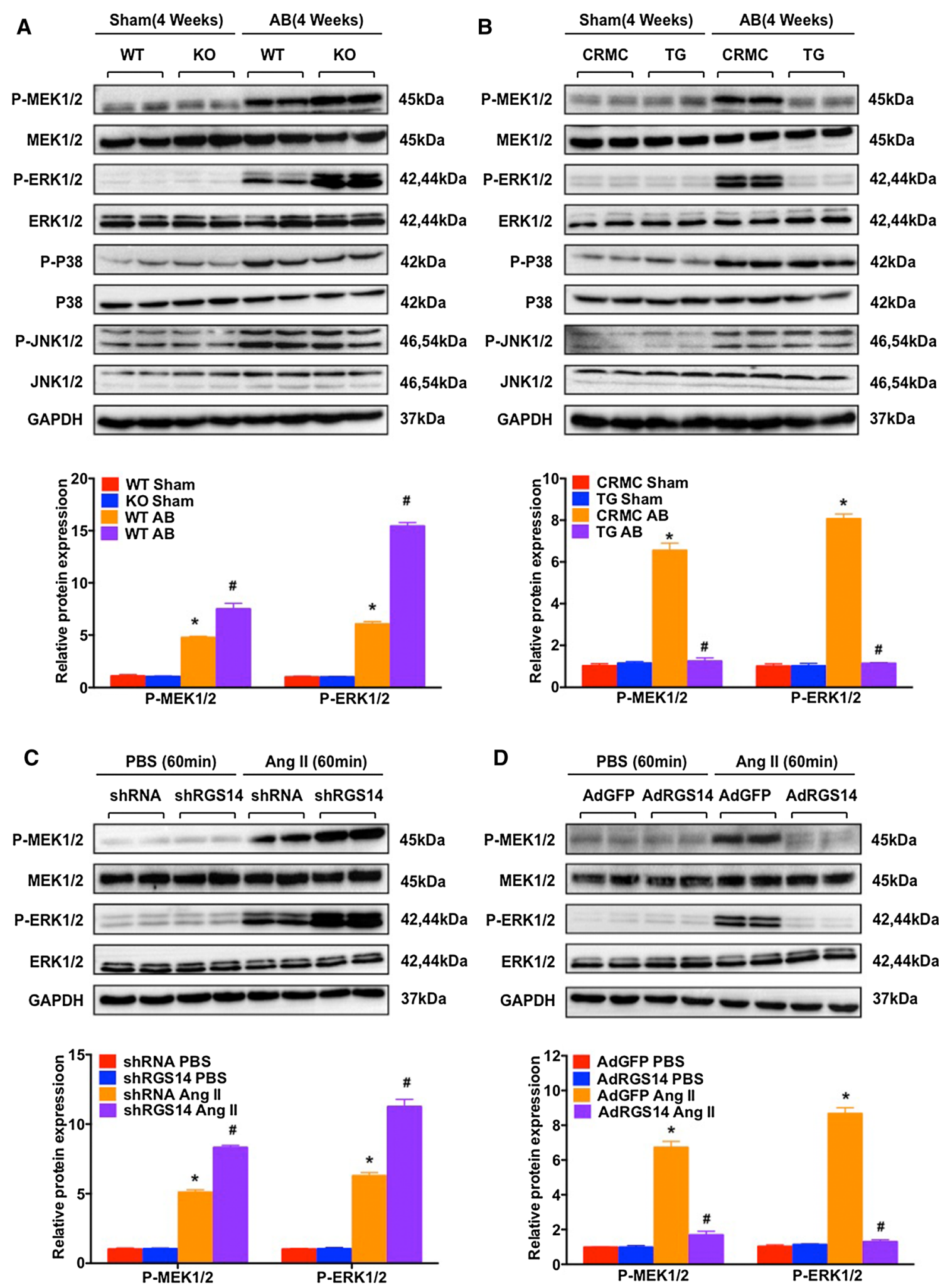
4Fig. 6 RGS14 inhibits the MEK-ERK1/2 signalling pathway in cardiomyocytes and experimental mice. Representative western blots and quantitative analysis of the phosphorylated and total protein levels of MEK1/2, ERK1/2, JNK1/2, and p38 after sham treatment or $\mathrm{AB}$ treatment in WT and $R G S 14^{-1-}$ mice $(n=4$ mice per group; ${ }^{*} P<0.05$ vs. WT/sham; ${ }^{\#} P<0.05$ vs. WT/AB) (a) and in CRMC and $R G S 14$-TG mice at week four $(n=4$ mice per group; $* P<0.05$ vs. CRMC/sham; ${ }^{\#} P<0.05$ vs. CRMC/AB) (b). Levels of phosphorylated and total MEK1/2 and ERK1/2 proteins in samples of NRCMs infected with AdshRGS14 (c) or AdRGS14 (d) and treated with Ang II $\left(n=4,{ }^{*} P<0.05\right.$ vs. AdshRNA/PBS or AdGFP/PBS; ${ }^{\#} P<0.05$ vs. AdshRNA/Ang II or AdGFP/Ang II). Upper Representative blots; lower quantitative results. The data are presented as the mean $\pm \mathrm{SD}$

values according to the echocardiograph indicated deteriorated cardiac function in the DTG group compared with the RGS14-TG group (Fig. 8g-i). Moreover, the heart areas, cardiomyocyte cross-sectional areas, and cardiac fibrosis volumes were significantly up-regulated in the DTG mice, as shown in Fig. 8j-1, compared with the RGS14-TG mice. These parameters were equal in the DTG mice and the CaMEK1 mice (Fig. 8d-1). Our results demonstrate that targeted MEK1 activation abolishes the protective effects of RGS14 on cardiac remodelling after AB surgery. Therefore, our findings indicate that the protective role of RGS14 in pathological cardiac remodelling is at least in part due to the inhibition of MEK1 signalling.

\section{Discussion}

We performed an exploratory study to determine the role of RGS14 in cardiac remodelling and its underlying mechanism by gain-of-function and loss-of-function approaches. Our major findings demonstrated that the disruption of RGS14 resulted in an exaggerated pathological cardiac remodelling response, whereas the overexpression of RGS14 alleviated the cardiac hypertrophy and dysfunction induced by aortic banding operation. Furthermore, the results supported that RGS14-mediated cardio-protection was at least partly attributed to inhibition of the MEKERK1/2 signalling pathway. For the first time, our results demonstrated a critical role of RGS14 in the pathophysiology process of cardiac remodelling and heart failure.

RGS proteins are believed to reduce the duration and power of GPCRs' effects and, therefore, participate in pathophysiology processes [13,54]. Previous studies have demonstrated that RGS14 is expressed in the heart, although its function in the cardiovascular system remains unknown $[25,55,68]$. We first observed that the protein level of RGS14 was decreased in the hearts of DCM patients, which suggested that RGS14 might be involved in the process of cardiac hypertrophy. Because biomechanical stress and neurohumoral factors are major triggers of cardiac hypertrophy, aortic banding and angiotensin II were used to treat animal models and NRCMs, respectively. The results showed that RGS14 was significantly decreased after aortic banding or angiotensin II stimulation. Furthermore, RGS14 knockout aggravated cardiac hypertrophy after aortic banding, and RGS14 cardiomyocyte-specific overexpression significantly alleviated cardiac remodelling in vivo, which revealed a protective role of RGS14 in cardiac remodelling.

Molecular mechanism research revealed that MAPK signalling mediated the effect of RGS14 on cardiac hypertrophy. The MAPK cascade comprises a sequence of successive kinases, including p38, JNKs, and ERKs $[18,39,45]$. All three major MAPK pathways are activated in cardiac tissue in pressure overload-induced animal models and in humans with heart failure $[14,16]$. It has been reported that JNK is an important mediator of pathological cardiac hypertrophy, although in the animal model with a loss of functional MEK4 (up-stream of JNK), JNK shows controversial effect on cardiac remodelling $[10,35]$. P38 plays an essential role in fibrosis, apoptosis, inflammation, and the production of cytokines, but the existing data concerning the role of p38 in hypertrophy in the heart are difficult to reconcile [1]. We found that the activation of MEK-ERK1/2 was inhibited by cardiac RGS14 overexpression, whereas the deletion of RGS14 further enhanced the activation of MEK-ERK1/2 after chronic pressure overload. However, RGS14 did not affect the phosphorylation of p38 and JNK1/2, which indicated that ERK1/2 was the sole downstream target of RGS14 in cardiac remodelling. Furthermore, U0126 mitigated the aggravated effects of RGS14 deficiency on cardiac remodelling, whereas targeted MEK1 activation negated the protective effects of RGS14 on cardiac remodelling. Taken together, mechanistic inhibition of MEK-ERK1/2 signalling could largely account for the cardio-protective effect of RGS14 on pathological cardiac remodelling in the current study.

It is well accepted that the MEK-ERK1/2 signalling pathways are central mediators of cardiac hypertrophy $[16,18,27,38,42]$. In the present study, the inhibition of MEK reversed the poor outcomes of cardiac hypertrophy, fibrosis, and dysfunction, whereas the overexpression of MEK1 in CaMEK1 transgenic mice promoted cardiac hypertrophy. These results suggested a promoting role of 
A
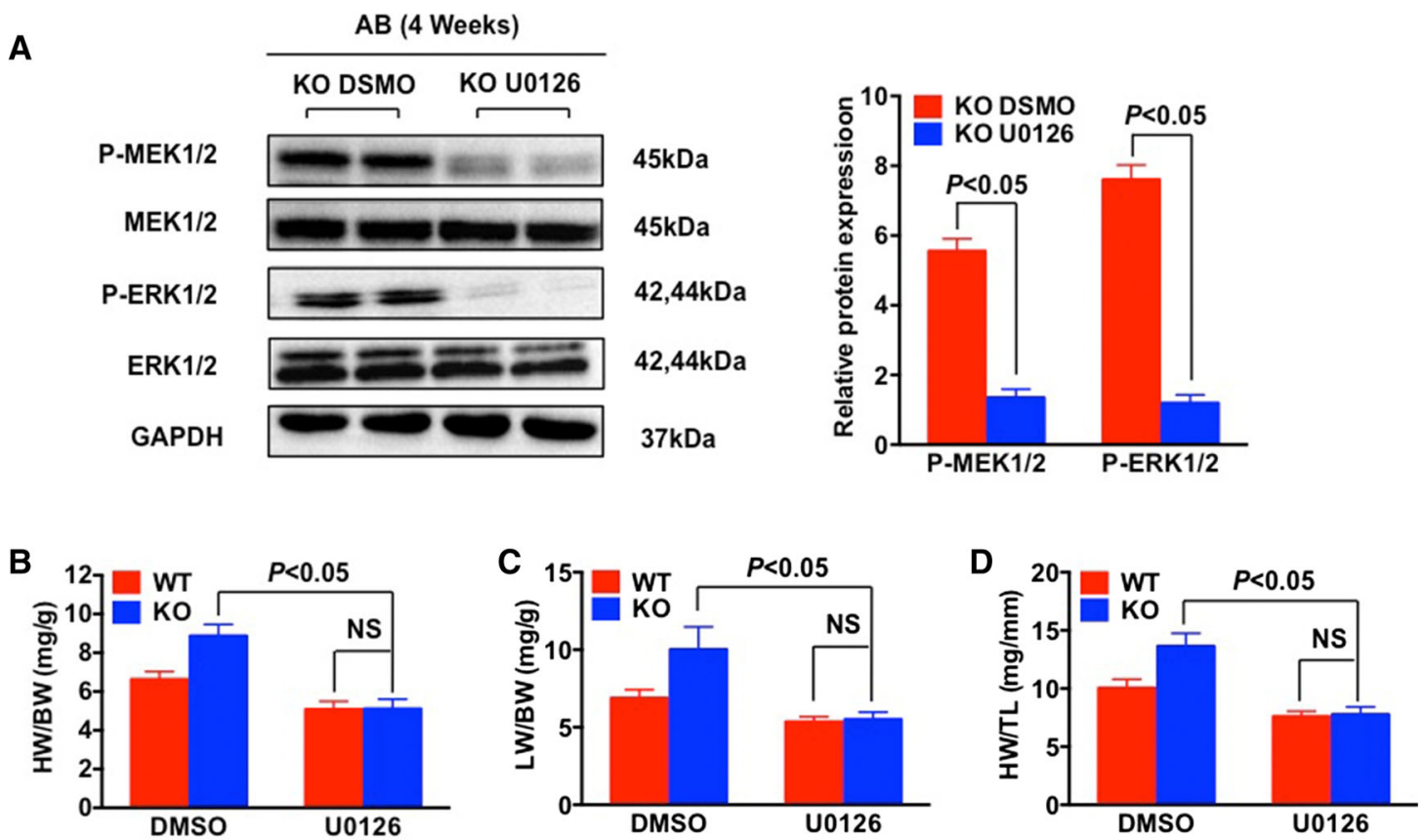

E
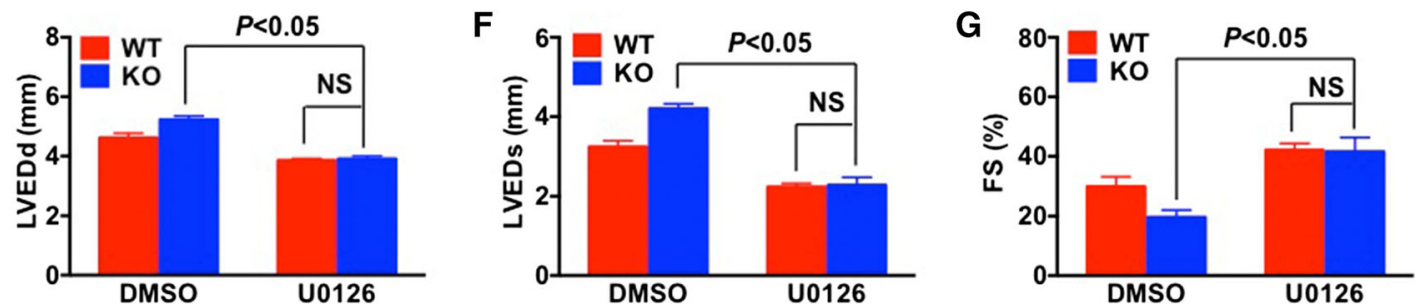

H

$A B$ (4 weeks)

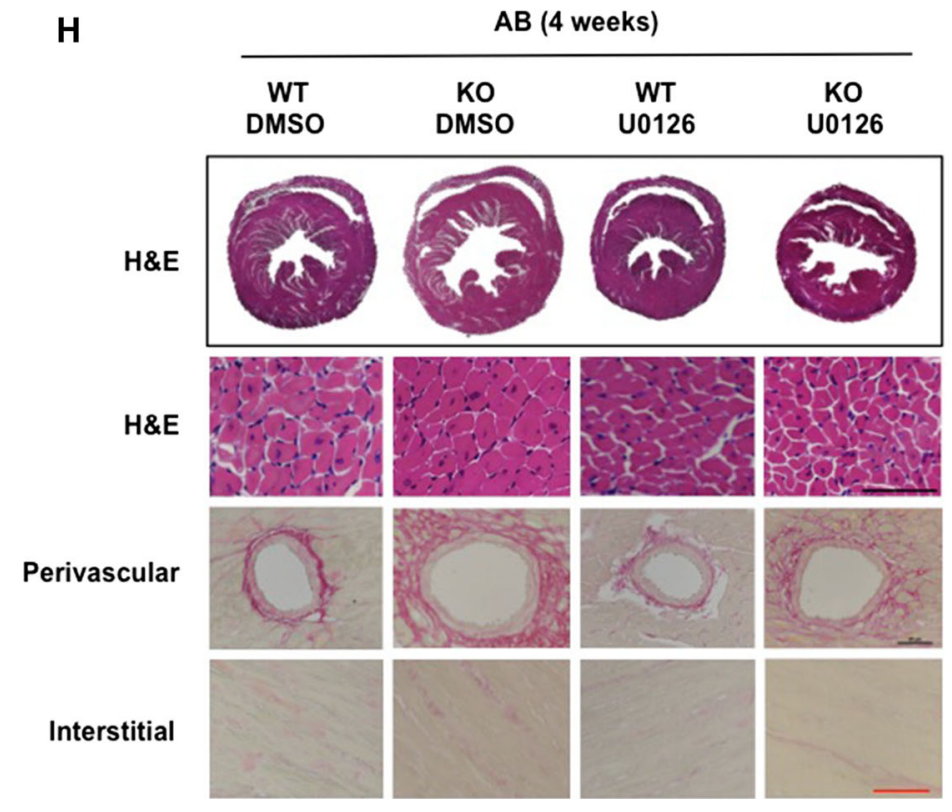

I

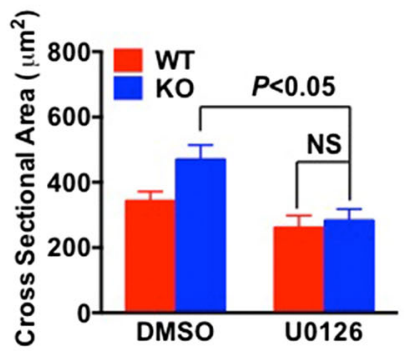

Perivascula

Interstitial

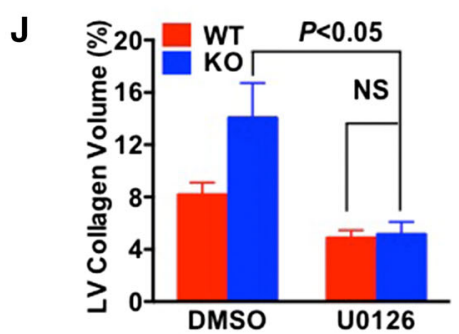


4Fig. 7 Inhibition of MEK1/2 abolishes cardiac abnormalities in $R G S 14^{-1-}$ mice in response to pressure overload. a Representative western blotting and quantitative analysis of the phosphorylation levels of MEK1/2 and ERK1/2 in $R G S 14^{-1-}$ mice treated with an inhibitor of MEK (U0126) compared with DMSO in response to $\mathrm{AB}$ treatment ( $n=4$ mice per group). b-d The HW/BW, LW/BW, and HW/TL ratios in $R G S 14^{+/+}$and $R G S 14^{-/-}$mice treated with U0126 or DMSO 4 weeks after AB surgery. ( $n=9$ for each group). eg Echocardiographic parameters (LVEDd, LVESd, and FS\%) for $R G S 14^{+/+}$and $R G S 14^{-1-}$ mice treated with U0126 or DMSO after AB surgery ( $n=8-9$ per group). h Sections of hearts from $R G S 14^{+/+}$ and $R G S 14^{-1-}$ mice treated with U0126 or DMSO subjected to AB surgery were stained with H\&E (first row: scale bar $50 \mu \mathrm{m}$ ) and PSR (second row and third row: scale bars $50 \mu \mathrm{m}$ ) to analyze cardiac hypertrophy and fibrosis ( $n=5$ per group). i Quantification of cardiomyocyte cross-sectional area in $R G S 14^{+/+}$and $R G S 14^{-1-}$ mice treated with $\mathrm{U} 0126$ or DMSO after AB surgery ( $n=5$ per group). j Quantification of fibrosis areas in $R G S 14^{+/+}$and $R G S 14^{-1-}$ mice treated with $\mathrm{U} 0126$ or DMSO after AB surgery ( $n=5$ per group). $N S$ no significance. The data are presented as the mean $\pm \mathrm{SD}$

MEK-ERK1/2 in pressure overload-induced remodelling. There are reports demonstrating that activated MEKERK1/2 signalling resulted in concentric hypertrophy in MEK1 transgenic mice. Mice lacking ERK1/2 in the heart by a genetic approach showed eccentric cardiac growth with and without the AngII stimulation [4, 5, 27]. Therefore, it appeared that MEK-ERK1/2 induced a compensatory mechanism from eccentric to concentric status in cardiac hypertrophy. The effectiveness and specificity of the pharmacological inhibitory and loss-of-function approach in ERK might account for this difference. Furthermore, MEK-ERK might play different roles in cardiac remodelling when receiving different stimuli. Experiments on baseline activation, post-stimulus peak activation, or activation amplitude of MEK-ERK would provide new insight into the role of MEK-ERK pathway in cardiac function.

How RGS14 exhibits an inhibitory effect on the MEK1/ 2-ERK1/2 cascade in cardiac remodelling remains unclear. In addition to the conserved RGS domain, RGS14 contains the GoLoco domain and two Ras/Rap-binding domains $[9,57,58,69]$. The RGS domain and GoLoco motif proteins in RGS14 are referred to bind to Gi and inhibit its guanine nucleotide dissociation [58]. Gi is best described as the inhibitory isoform of $\mathrm{G} \alpha$ that suppresses adenylate cyclase activity, leading to decreased cAMP accumulation [2, 63]; however, to our knowledge, there are no data demonstrating that the loss of $\mathrm{Gi}$ regulates cardiac remodelling. Several studies have indicated that over-activation of Ras signalling induces pathological cardiac remodelling through the MER-ERK cascade pathway in vivo and in vitro [17, 20, 42]. In addition, the Ras- binding domain was defined as the binding site of RGS14 when regulating the MAPK signalling pathway in a synaptic plasticity study [61]. Therefore, it is possible that the Ras-binding domain of RGS14 is responsible for the inhibitory effect of RGS14 on the MEK-ERK1/2 cascade in cardiac remodelling. The specific mechanism distinguishes RGS14 as the special protein among the RGS proteins in cardiac remodelling, although the further implication needs more exploration.

RGS2, 3, 4, and 5, which belong to the R4/B subfamily, have been demonstrated to play a protective role in pressure overload-induced cardiac remodelling $[31,36,47,52,53,62]$. In the present study, the levels of RGS 2, 3, 4, and 5 were not changed in the RGS14-KO mice compared with the wild-type mice or in the RGS14TG mice compared with the CRMC mice. Therefore, it appeared that there was no complementary mechanism between RGS14 and other RGS proteins in cardiac remodelling.

RGS14 was expressed both in cardiomyocytes and cardiac fibroblasts, although the level of RGS14 was unchanged in fibroblasts in response to angiotensin II stimuli in the current study, suggesting that profibrotic signalling in fibroblasts might not be linked directly to RGS14 in pathological processes. RGS14 overexpression only in cardiomyocytes appeared to be sufficient to protect against pressure overload-induced cardiac remodelling. Previous studies have indicated that activated Ras-MEKERK1/2 from cardiomyocytes could markedly reduce fibrosis in response to pressure overload [60, 67], which might explain the underlying mechanism of RGS14 on cardiac fibrosis. We are unable to exclude the possibility that RGS14 in fibroblasts might contribute to cardiac hypertrophy via other pathways.

A limitation of this study is that the up-stream regulatory mechanism for RGS14-mediated protection of heart hypertrophy was not elucidated, because we only focused on the effect of RGS14 on the development of heart remodelling in this study. Numerous reports have indicated that RGS could be regulated by a variety of factors, including GPCR activation, second messengers, and epigenetic changes in different cell types [46, 59]. RGS appeared to be a common downstream mediator in heart remodelling. The present study suggested that RGS14 could respond to pressure overload and Ang II, but more details should be studied in future.

Our research demonstrated that RGS14 protected the development of cardiac hypertrophy via suppressing the MEK-ERK1/2 signalling pathway in vitro and in vivo. These observations implied that RGS14 is a newly 
A

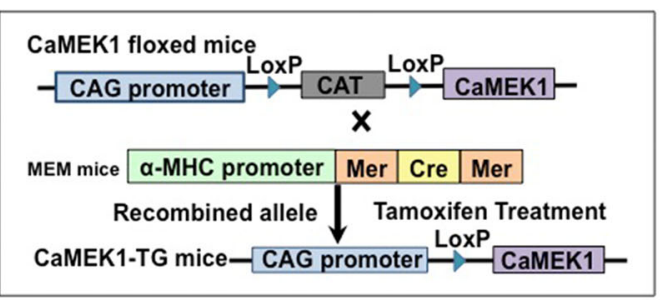

C

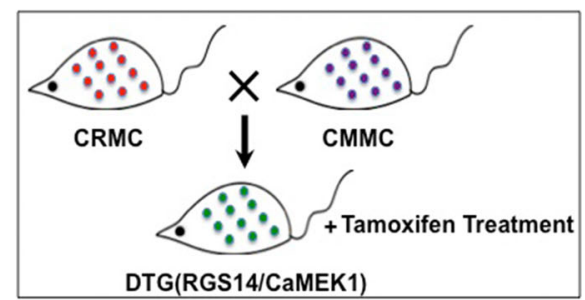

B

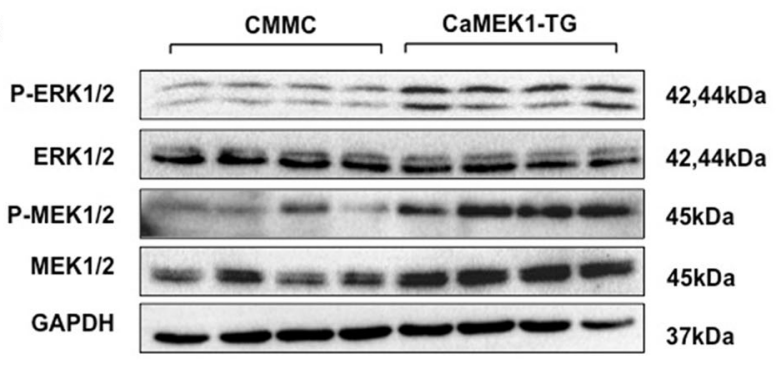

D

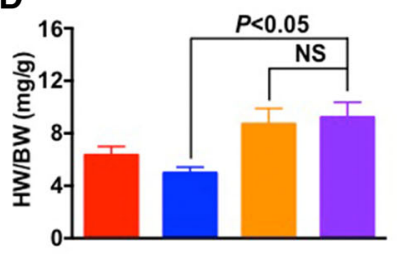

G

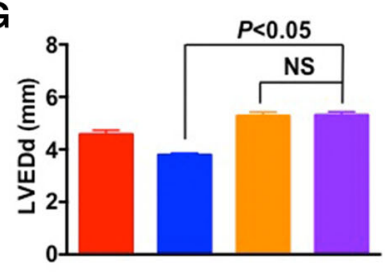

E

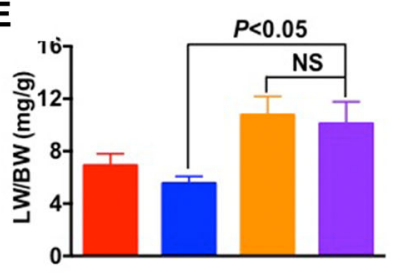

H

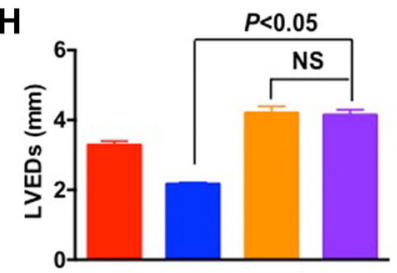

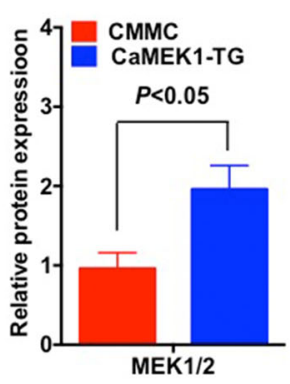

F

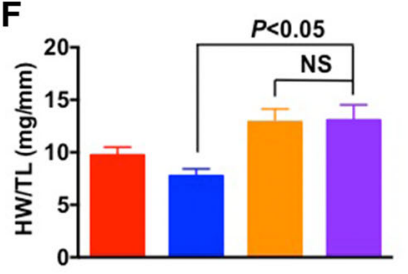

I

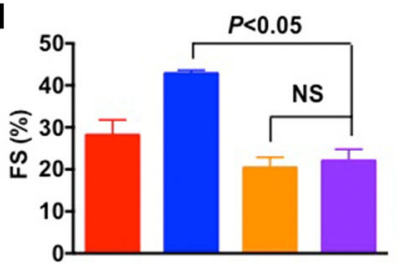

J

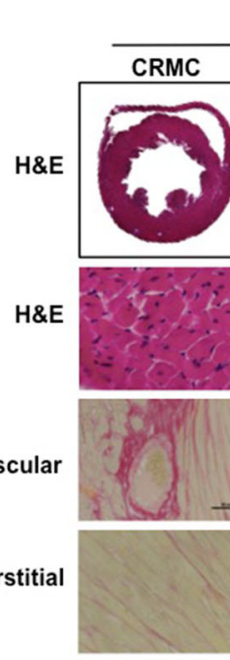

AB (4 weeks)

RGS14-TG CaMEK1-TG DTG
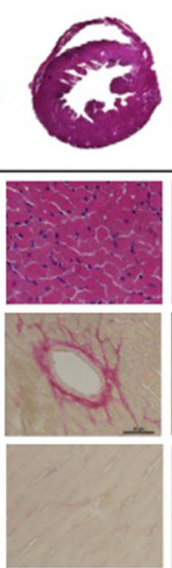
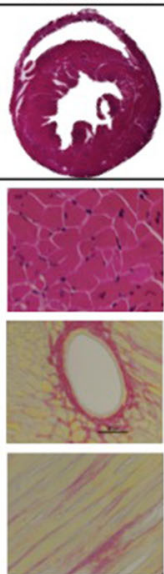
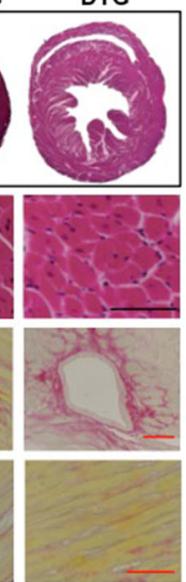

K

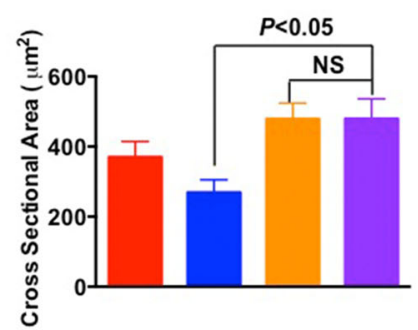

L

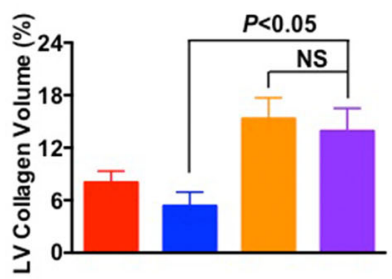


4Fig. 8 Overexpression of MEK1 negates the protective effects of RGS14 on cardiac hypertrophy in RGS14-TG mice. a A schematic diagram of the generation of TG mice with cardiac-specific expression of MEK1. b Representative western blots of CMMC and CaMEK1-TG mice 4 weeks after AB surgery ( $n=4$ per group). The level of MEK was significantly increased in the CaMEK1-TG mice compared with the control group. c Breeding strategy for the production of CaMEK1/RGS14 double transgenic mice. d-f The HW/BW, LW/BW, and HW/TL ratios in CRMC, RGS14-TG, CaMEK1-TG, and DTG mice subjected to AB surgery $(n=8-9$ for each group), respectively. $\mathbf{g}-\mathbf{i}$ Cardiac function (LVEDd, LVESd, and FS\%) as measured by echocardiography of CRMC, RGS14-TG, CaMEK1-TG, and DTG mice after AB treatment $(n=6-8$ per group). $\mathbf{j}$ Sections of hearts from CRMC, RGS14-TG, CaMEK1-TG, and DTG mice subjected to AB surgery were stained with $\mathrm{H} \& \mathrm{E}$ (first row: scale bar $50 \mu \mathrm{m}$ ) and PSR (second row and third row: scale bars $50 \mu \mathrm{m}$ ) to analyze cardiac hypertrophy and fibrosis ( $n=5$ per group). k Quantification of cardiomyocyte cross-sectional area in AB-treated CRMC, RGS14-TG, CaMEK1-TG, and DTG mice ( $n=5$ per group). 1 Quantification of the fibrosis areas in AB-treated CRMC, RGS14TG, CaMEK1-TG, and DTG mice ( $n=5$ per group). $N S$ no significance. The data are presented as the mean \pm SD

appreciated partner of GPCRs in the heart. RGS proteins could serve as potential therapeutic targets for cardiac hypertrophy and heart failure.

Acknowledgments This study was funded by the National Science and Technology Major Projects for "Major New Drugs Innovation and Development" in China (2012ZX09303014-001); the National Key Technology R\&D Program (2012BAI37B05); the National Natural Science Foundation of China (81273594, 81503071, $81470535,81570271)$; and the Hunan Provincial Innovation Foundation for Postgraduates (CX2014B108). We thank Ding-sheng Jiang, Xiao-jing Zhang, Jun Gong, Rui Zhang, Xue-yong Zhu, Yan Zhang, Ling Huang, Ya Deng, and Xin Zhang for providing experimental technological assistance.

\section{Compliance with ethical standards}

Conflict of interest On behalf of all authors, the corresponding author states that there is no conflict of interest.

Open Access This article is distributed under the terms of the Creative Commons Attribution 4.0 International License (http://crea tivecommons.org/licenses/by/4.0/), which permits unrestricted use, distribution, and reproduction in any medium, provided you give appropriate credit to the original author(s) and the source, provide a link to the Creative Commons license, and indicate if changes were made.

\section{References}

1. Arabacilar P, Marber M (2015) The case for inhibiting p38 mitogen-activated protein kinase in heart failure. Front Pharmacol 6:102-108. doi:10.3389/fphar.2015.00102

2. Bohm M, Gierschik P, Jakobs KH, Pieske B, Schnabel P, Ungerer M, Erdmann E (1990) Increase of Gi alpha in human hearts with dilated but not ischemic cardiomyopathy. Circulation 82:1249-1265. doi:10.1161/01.CIR.82.4.1249
3. Booz GW, Day JN, Baker KM (2002) Interplay between the cardiac renin angiotensin system and JAK-STAT signaling: role in cardiac hypertrophy, ischemia/reperfusion dysfunction, and heart failure. J Mol Cell Cardiol 34:1443-1453. doi:10.1006/ jmcc. 2002.2076

4. Bueno OF, De Windt LJ, Tymitz KM, Witt SA, Kimball TR, Klevitsky R, Hewett TE, Jones SP, Lefer DJ, Peng CF, Kitsis RN, Molkentin JD (2000) The MEK1-ERK1/2 signaling pathway promotes compensated cardiac hypertrophy in transgenic mice. EMBO J 19:6341-6350. doi:10.1093/emboj/19.23.6341

5. Bueno OF, Molkentin JD (2002) Involvement of extracellular signal-regulated kinases $1 / 2$ in cardiac hypertrophy and cell death. Circ Res 91:776-781. doi:10.1161/01.RES.0000038488. 38975.1A

6. Bui AL, Horwich TB, Fonarow GC (2011) Epidemiology and risk profile of heart failure. Nat. Rev. Cardiol 8:30-41. doi:10. 1038/nrcardio.2010.165

7. Burnier M (2001) Angiotensin II type 1 receptor blockers. Circulation 103:904-912. doi:10.1161/01.CIR.103.6.904

8. Cho H, Kehrl JH (2007) Localization of Gia proteins in the centrosomes and at the midbody: implication for their role in cell division. J Cell Biol 178:245-255. doi:10.1083/jcb.200604114

9. Cho H, Kozasa T, Takekoshi K, De Gunzburg J, Kehrl JH (2000) RGS14, a GTPase-activating protein for Gi $\alpha$, attenuates Gi $\alpha$ - and G13 $\alpha$-mediated signaling pathways. Mol Pharmacol 58:569-576. doi:10.1124/mol.58.3.569

10. Choukroun G, Hajjar R, Fry S, del Monte F, Haq S, Guerrero JL, Picard M, Rosenzweig A, Force T (1999) Regulation of cardiac hypertrophy in vivo by the stress-activated protein kinases/c-Jun NH2-terminal kinases. J Clin Invest 104:391-398. doi:10.1172/ JCI6350

11. Clerk A, Cullingford TE, Fuller SJ, Giraldo A, Markou T, Pikkarainen S, Sugden PH (2007) Signaling pathways mediating cardiac myocyte gene expression in physiological and stress responses. J Cell Physiol 212:311-322. doi:10.1002/jcp.21094

12. Creemers EE, Pinto YM (2011) Molecular mechanisms that control interstitial fibrosis in the pressure-overloaded heart. Cardiovasc Res 89:265-272. doi:10.1093/cvr/cvq308

13. Doupnik CA, Xu T, Shinaman JM (2001) Profile of RGS expression in single rat atrial myocytes. Biochim Biophys Acta 1522:97-107. doi:10.1016/S0167-4781(01)00342-6

14. Esposito G, Prasad SV, Rapacciuolo A, Mao L, Koch WJ, Rockman HA (2001) Cardiac overexpression of a G(q) inhibitor blocks induction of extracellular signal-regulated kinase and c-Jun NH(2)-terminal kinase activity in in vivo pressure overload. Circulation 103:1453-1458. doi:10.1161/01.CIR.103.10.1453

15. Flesch M, Schwinger RH, Schnabel P, Schiffer F, van Gelder I, Bavendiek U, Sudkamp M, Kuhn- Regnier F, Bohm M (1996) Sarcoplasmic reticulum $\mathrm{Ca}^{2+}$ ATPase and phospholamban mRNA and protein levels in end-stage heart failure due to ischemic or dilated cardiomyopathy. J Mol Med 74:321-332

16. Haq S, Choukroun G, Lim H, Tymitz KM, del Monte F, Gwathmey J, Grazette L, Michael A, Hajjar R, Force T, Molkentin JD (2001) Differential activation of signal transduction pathways in human hearts with hypertrophy versus advanced heart failure. Circulation 103:670-677. doi:10.1161/01.CIR.103. 5.670

17. Harris IS, Zhang S, Treskov I, Kovacs A, Weinheimer C, Muslin AJ (2004) Raf-1 kinase is required for cardiac hypertrophy and cardiomyocyte survival in response to pressure overload. Circulation 110:718-723. doi:10.1161/01.CIR.0000138190.50127.6A

18. Heineke J, Molkentin JD (2006) Regulation of cardiac hypertrophy by intracellular signalling pathways. Nat Rev Mol Cell Biol 7:589-600. doi:10.1038/nrm1983

19. Hercule HC, Tank J, Plehm R, Wellner M, da Costa Goncalves AC, Gollasch M, Diedrich A, Jordan J, Luft FC, Gross V (2007) 
Regulator of $\mathrm{G}$ protein signalling 2 ameliorates angiotensin IIinduced hypertension in mice. Exp Physiol 92:1014-1022. doi:10.1113/expphysiol.2007.038240

20. Ho PD, Zechner DK, He H, Dillmann WH, Glembotski CC, McDonough PM (1998) The Raf-MEK-ERK cascade represents a common pathway for alteration of intracellular calcium by Ras and protein kinase $\mathrm{C}$ in cardiac myocytes. J Biol Chem 273:21730-21735. doi:10.1074/jbc.273.34.21730

21. Jiang DS, Liu Y, Zhou H, Zhang Y, Zhang XD, Zhang XF, Chen K, Gao L, Peng J, Gong H, Chen Y, Yang Q, Liu PP, Fan GC, Zou Y, Li H (2014) Interferon regulatory factor 7 functions as a novel negative regulator of pathological cardiac hypertrophy. Hypertension 63:713-722. doi:10.1161/HYPERTENSIONAHA. 113.02653

22. Jiang DS, Luo YX, Zhang R, Zhang XD, Chen HZ, Zhang Y, Chen K, Zhang SM, Fan GC, Liu PP, Liu DP, Li H (2014) Interferon regulatory factor 9 protects against cardiac hypertrophy by targeting myocardin. Hypertension 63:119-127. doi:10. 1161/HYPERTENSIONAHA.113.02083

23. Jiang DS, Wei X, Zhang XF, Liu Y, Zhang Y, Chen K, Gao L, Zhou H, Zhu XH, Liu PP, Bond Lau W, Ma X, Zou Y, Zhang XD, Fan GC, Li H (2014) IRF8 suppresses pathological cardiac remodelling by inhibiting calcineurin signalling. Nat Commun 5:3303-3316. doi: $10.1038 /$ ncomms 4303

24. Jiang X, Deng KQ, Luo Y, Jiang DS, Gao L, Zhang XF, Zhang P, Zhao GN, Zhu X, Li H (2015) Tumor necrosis factor receptorassociated factor 3 is a positive regulator of pathological cardiac hypertrophy. Hypertension 66:356-367. doi:10.1161/HYPER TENSIONAHA.115.05469

25. Kardestuncer T, Wu H, Lim AL, Neer EJ (1998) Cardiac myocytes express mRNA for ten RGS proteins: changes in RGS mRNA expression in ventricular myocytes and cultured atria. FEBS Lett 438:285-288. doi:10.1016/S0014-5793(98)01319-2

26. Katz AM (1990) Cardiomyopathy of overload: a major determinant of prognosis in congestive heart failure. $\mathrm{N}$ Engl $\mathrm{J}$ Med 322:100-110. doi:10.1056/NEJM199001113220206

27. Kehat I, Davis J, Tiburcy M, Accornero F, Saba-El-Leil MK, Maillet M, York AJ, Lorenz JN, Zimmermann WH, Meloche S, Molkentin JD (2011) Extracellular signal-regulated kinases 1 and 2 regulate the balance between eccentric and concentric cardiac growth. Circ Res 108:1761-1783. doi:10.1161/CIRCRESAHA. 110.231514

28. Klaiber M, Kruse M, Völker K, Schröter J, Feil R, Freichel M, Gerling A, Feil S, Dietrich A, Londoño JE, Baba HA, Abramowitz J, Birnbaumer L, Penninger JM, Pongs O, Kuhn M (2010) Novel insights into the mechanisms mediating the local antihypertrophic effects of cardiac atrial natriuretic peptide: role of cGMP-dependent protein kinase and RGS2. Basic Res Cardiol 105:583-595. doi:10.1007/s00395-010-0098-Z

29. Ladds G, Zervou S, Vatish M, Thornton S, Davey J (2009) Regulators of $\mathrm{G}$ protein signalling proteins in the human myometrium. Eur J Pharmacol 610:23-28. doi:10.1016/j.ejphar.2009. 03.042

30. Lee SE, Simons SB, Heldt SA, Zhao M, Schroeder JP, Vellano CP, Cowan DP, Ramineni S, Yates CK, Feng Y, Smith Y, Sweatt JD, Weinshenker D, Ressler KJ, Dudek SM, Hepler JR (2010) RGS14 is a natural suppressor of both synaptic plasticity in CA2 neurons and hippocampal-based learning and memory. Proc Natl Acad Sci USA 107:16994-16998. doi:10.1073/pnas.1005362107

31. Li H, He C, Feng J, Zhang Y, Tang Q, Bian Z, Bai X, Zhou H, Jiang H, Heximer SP, Qin M, Huang H, Liu PP, Huang C (2010) Regulator of $\mathrm{G}$ protein signaling 5 protects against cardiac hypertrophy and fibrosis during biomechanical stress of pressure overload. Proc Natl Acad Sci USA 107:13818-13823. doi:10. 1073/pnas. 1008397107
32. Li Y, Li XH, Huang ZJ, Tang XH, Liu JJ, Yuan H (2014) Metoprolol restores expression and vasodilatation function of AT2R in spontaneously hypertensive rats. J Cardiovasc Pharmacol 63:252-258. doi:10.1097/FJC.0000000000000042

33. Li Y, Li XH, Huang ZJ, Yang GP, Zhang GG, Zhao SP, Guo Y, Lu SJ, Ma JL, Meng FB, Chen P, Yuan H (2015) A randomized, double blind, placebo-controlled, multicenter phase II trial of Allisartan Isoproxil in essential hypertensive population at lowmedium risk. PLoS One 10:e0117560. doi:10.1371/journal.pone. 0117560

34. Lim J, Thompson J, May RC, Hotchin NA, Caron E (2013) Regulator of G-protein signalling-14 (RGS14) regulates the activation of $\alpha \mathrm{M} \beta 2$ integrin during phagocytosis. PLoS One 8:e69163. doi:10.1371/journal.pone.0069163

35. Liu W, Zi M, Jin J, Prehar S, Oceandy D, Kimura TE, Lei M, Neyses L, Weston AH, Cartwright EJ, Wang X (2009) Cardiacspecific deletion of MKK4 reveals its role in pathological hypertrophic remodeling but not in physiological cardiac growth. Circ Res 104:905-914. doi:10.1161/CIRCRESAHA.108.188292

36. Liu Y, Huang H, Zhang Y, Zhu XY, Zhang R, Guan LH, Tang Q, Jiang H, Huang C (2014) Regulator of $G$ protein signaling 3 protects against cardiac hypertrophy in mice. J Cell Biochem 115:977-986. doi:10.1002/jcb.24741

37. Liu Y, Jiang XL, Liu Y, Jiang DS, Zhang Y, Zhang R, Chen Y, Yang Q, Zhang XD, Fan GC, Li H (2014) Toll-interacting protein (Tollip) negatively regulates pressure overload-induced ventricular hypertrophy in mice. Cardiovasc Res 101:87-96. doi:10. $1093 / \mathrm{cvr} / \mathrm{cvt} 232$

38. Lorenz K, Schmitt JP, Schmitteckert EM, Lohse MJ (2009) A new type of ERK1/2 autophosphorylation causes cardiac hypertrophy. Nat Med 15:75-83. doi:10.1038/nm.1893

39. Lu J, Bian ZY, Zhang R, Zhang Y, Liu C, Yan L, Zhang SM, Jiang DS, Wei X, Zhu XH, Chen M, Wang AB, Chen Y, Yang Q, Liu PP, Li H (2013) Interferon regulatory factor 3 is a negative regulator of pathological cardiac hypertrophy. Basic Res Cardiol 108:326-338. doi:10.1007/s00395-012-0326-9

40. Martin-McCaffrey L, Willard FS, Oliveira-dos-Santos AJ, Natale DR, Snow BE, Kimple RJ, Pajak A, Watson AJ, Dagnino L, Penninger JM, Siderovski DP, D'Souza SJ (2004) RGS14 is a mitotic spindle protein essential from the first division of the mammalian zygote. Dev Cell 7:763-769. doi:10.1016/j.devcel. 2004.10.004

41. Martin-McCaffrey L, Willard FS, Pajak A, Dagnino L, Siderovski DP, D'Souza SJ (2005) RGS14 is a microtubule-associated protein. Cell Cycle 4:953-960. doi:10.4161/cc.4.7.1787

42. Mitchell S, Ota A, Foster W, Zhang B, Fang Z, Patel S, Nelson SF, Horvath S, Wang Y (2006) Distinct gene expression profiles in adult mouse heart following targeted MAP kinase activation. Physiol Genomics 25:50-59. doi:10.1152/physiolgenomics.00224.2005

43. Mittmann C, Chung $\mathrm{CH}$, Hoppner G, Michalek C, Nose M, Schuler C, Schuh A, Eschenhagen T, Weil J, Pieske B, Hirt S, Wieland T (2002) Expression of ten RGS proteins in human myocardium: functional characterization of an upregulation of RGS4 in heart failure. Cardiovasc Res 55:778-786. doi:10.1016/ S0008-6363(02)00459-5

44. Mozaffarian D, Benjamin EJ, Go AS, Arnett DK, Blaha MJ, Cushman M, de Ferranti S, Després JP, Fullerton HJ, Howard VJ, Huffman MD, Judd SE, Kissela BM, Lackland DT, Lichtman JH, Lisabeth LD, Liu S, Mackey RH, Matchar DB, McGuire DK, Mohler ER 3rd, Moy CS, Muntner P, Mussolino ME, Nasir K, Neumar RW, Nichol G, Palaniappan L, Pandey DK, Reeves MJ, Rodriguez CJ, Sorlie PD, Stein J, Towfighi A, Turan TN, Virani SS, Willey JZ, Woo D, Yeh RW, Turner MB, American Heart Association Statistics Committee and Stroke Statistics Subcommittee (2015) Heart disease and stroke statistics-2015 update: a 
report from the American Heart Association. Circulation 131:e29-322. doi:10.1161/CIR.0000000000000152

45. Muslin AJ (2008) MAPK signalling in cardiovascular health and disease: molecular mechanisms and therapeutic targets. Clin Sci (Lond) 115:203-218. doi:10.1042/CS20070430

46. Nunn C, Zou MX, Sobiesiak AJ, Roy AA, Kirshenbaum LA, Chidiac P (2010) RGS2 inhibits beta-adrenergic receptor-induced cardiomyocyte hypertrophy. Cell Signal 22:1231-1239. doi:10. 1016/j.cellsig.2010.03.015

47. Park-Windhol C, Zhang P, Zhu M, Su J, Chaves L Jr, Maldonado AE, King ME, Rickey L, Cullen D, Mende U (2012) Gq/11mediated signaling and hypertrophy in mice with cardiac-specific transgenic expression of regulator of G-protein signaling 2. PLoS One 7:e40048. doi:10.1371/journal.pone.0040048

48. Pandya K, Kim HS, Smithies O (2006) Fibrosis, not cell size, delineates beta-myosin heavy chain reexpression during cardiac hypertrophy and normal aging in vivo. Proc Natl Acad Sci USA 103:16864-16869. doi:10.1073/pnas.0607700103

49. Posokhova E, Wydeven N, Allen KL, Wickman K, Martemyanov KA (2010) RGS6/Gß5 complex accelerates IKACh gating kinetics in atrial myocytes and modulates parasympathetic regulation of heart rate. Circ Res 107:1350-1354. doi:10.1161/CIR CRESAHA.110.224212

50. Qin M, Huang H, Wang T, Hu H, Liu Y, Cao H, Li H, Huang C (2012) Absence of Rgs5 prolongs cardiac repolarization and predisposes to ventricular tachyarrhythmia in mice. $\mathrm{J}$ Mol Cell Cardiol 53:880-890. doi:10.1016/j.yjmcc.2012.10.003

51. Riddle EL, Schwartzman RA, Bond M, Insel PA (2005) Multitasking RGS proteins in the heart: the next therapeutic target? Circ Res 96:401-411. doi:10.1161/01.RES.0000158287.49872.4e

52. Rogers JH, Tamirisa P, Kovacs A, Weinheimer C, Courtois M, Blumer KJ, Kelly DP, Muslin AJ (1999) RGS4 causes increased mortality and reduced cardiac hypertrophy in response to pressure overload. J Clin Invest 104:567-576. doi:10.1172/JCI6713

53. Rogers JH, Tsirka A, Kovacs A, Blumer KJ, Dorn GW 2nd, Muslin AJ (2001) RGS4 reduces contractile dysfunction and hypertrophic gene induction in Galpha q overexpressing mice. J Mol Cell Cardiol 33:209-218. doi:10.1006/jmcc.2000.1307

54. Sandra S, Graeme M (2015) G protein-coupled receptors: structure, signaling, and physiology. Cambridge University Press, Cambridge

55. Snow BE, Antonio L, Suggs S, Gutstein HB, Siderovski DP (1997) Molecular cloning and expression analysis of rat Rgs12 and Rgs14. Biochem Biophys Res Comm 233:770-777. doi:10. 1006/bbrc.1997.6537

56. Tham YK, Bernardo BC, Ooi JY, Weeks KL, McMullen JR (2015) Pathophysiology of cardiac hypertrophy and heart failure: signaling pathways and novel therapeutic targets. Arch Toxicol 89:1401-1438. doi:10.1007/s00204-015-1477-x

57. Traver S, Bidot C, Spassky N, Baltauss T, De Tand MF, Thomas JL, Zalc B, Janoueix-Lerosey I, Gunzburg JD (2000) RGS14 is a novel Rap effector that preferentially regulates the GTPase activity of galphao. Biochem J 350:19-29. doi:10.1042/ bj3500019
58. Traver S, Splingard A, Gaudriault G, De Gunzburg J (2004) The RGS (regulator of G-protein signalling) and GoLoco domains of RGS14 co-operate to regulate Gi-mediated signalling. Biochem J 379:627-632. doi:10.1042/bj20031889

59. Tuggle K, Ali MW, Salazar H, Hooks SB (2014) Regulator of G protein signaling transcript expression in human neural progenitor differentiation: R7 subfamily regulation by DNA methylation. Neurosignals 22:43-51. doi:10.1159/000362128

60. Ulm S, Liu W, Zi M, Tsui H, Chowdhury SK, Endo S, Satoh Y, Prehar S, Wang R, Cartwright EJ, Wang X (2014) Targeted deletion of ERK2 in cardiomyocytes attenuates hypertrophic response but provokes pathological stress induced cardiac dysfunction. J Mol Cell Cardiol 72:104-116. doi:10.1016/j.yjmcc. 2014.03.002

61. Vellano CP, Lee SE, Dudek SM, Hepler JR (2011) RGS14 at the interface of hippocampal signaling and synaptic plasticity. Trends Pharmacol Sci 32:666-674. doi:10.1016/j.tips.2011.07.005

62. Wang X, Adams LD, Pabón LM, Mahoney WM Jr, Beaudry D, Gunaje J, Geary RL, Deblois D, Schwartz SM (2008) RGS5, RGS4, and RGS2 expression and aortic contractibility are dynamically co-regulated during aortic banding-induced hypertrophy. J Mol Cell Cardiol 44:539-550. doi:10.1016/j.yjmcc. 2007.11.019

63. Wong YH, Federman A, Pace AM, Zachary I, Evans T, Pouyssegur J, Bourne HR (1991) Mutant alpha subunits of Gi2 inhibit cyclic AMP accumulation. Nature 351:63. doi:10.1038/ $351063 \mathrm{a} 0$

64. Wieland T, Mittmann C (2003) Regulators of G-protein signalling: multifunctional proteins with impact on signalling in the cardiovascular system. Pharmacol Ther 97:95-115. doi:10.1016/ S0163-7258(02)00326-1

65. Yang J, Huang J, Maity B, Gao Z, Lorca RA, Gudmundsson H, Li J, Stewart A, Swaminathan PD, Ibeawuchi SR, Shepherd A, Chen CK, Kutschke W, Mohler PJ, Mohapatra DP, Anderson ME, Fisher RA (2010) RGS6, a modulator of parasympathetic activation in heart. Circ Res 107:1345-1349. doi:10.1161/CIRCRE SAHA.110.224220

66. Yang J, Maity B, Huang J, Gao Z, Stewart A, Weiss RM, Anderson ME, Fisher RA (2013) G-protein inactivator RGS6 mediates myocardial cell apoptosis and cardiomyopathy caused by doxorubicin. Cancer Res 73:1662-1727. doi:10.1158/00085472.CAN-12-3453

67. Zheng M, Dilly K, Dos Santos Cruz J, Li M, Gu Y, Ursitti JA, Chen J, Ross J Jr, Chien KR, Lederer JW, Wang Y (2004) Sarcoplasmic reticulum calcium defect in Ras-induced hypertrophic cardiomyopathy heart. Am J Physiol Heart Circ Physiol 286:H424-H433. doi:10.1152/ajpheart.00110.2003

68. Zhang P, Mende U (2011) Regulators of G-protein signaling in the heart and their potential as therapeutic targets. Cir Res 109:320-333. doi:10.1161/CIRCRESAHA.110.231423

69. Zhao P, Nunn C, Ramineni S, Hepler JR, Chidiac P (2013) The Ras-binding domain region of RGS14 regulates its functional interactions with heterotrimeric $G$ proteins. J Cell Biochem 114:1414-1423. doi:10.1002/jcb.24483 